\title{
Heterogeneous Price Rigidities and Monetary Policy
}

\author{
Christopher Clayton \\ Harvard University \\ Xavier Jaravel \\ London School of Economics \\ Andreas Schaab \\ Harvard University
}

August, 2018

Please find the latest version here.

\begin{abstract}
This paper investigates the implications of heterogeneous price rigidities across sectors for the distributional and aggregate effects of monetary policy. First, we identify and characterize analytically a new set of earnings and expenditure channels of monetary policy that emerge in the presence of sectoral heterogeneity. Second, we establish empirically that (i) prices are more rigid in sectors selling to college-educated households, (ii) prices are more rigid in sectors employing college-educated households, and (iii) sectors that employ college-educated households also sell more to these households. These new facts suggest that monetary policy stabilizes sectors that matter relatively more for college-educated households, due to an expenditure channel (from (i)), an earnings channel (from (ii)), and their amplification by feedback loops (from (iii)). Finally, we develop a multi-sector incomplete-markets Heterogeneous Agent New Keynesian model, in which households of different education levels work and consume in different sectors. We quantify the aggregate and distributional effects from heterogeneous price rigidities using this model. In the baseline calibration, we find that the consumption of college-educated households is $22 \%$ more sensitive to monetary policy shocks as that of non-college households, while the aggregate real effect of monetary policy is $5 \%$ stronger than with homogeneous price rigidities.
\end{abstract}




\section{Introduction}

What are the aggregate and distributional effects of monetary policy? Despite extensive research, the answer to this question remains debated. Previous work has investigated the distributional effects of monetary policy through a variety of channels, such as differences between savers and debtors (e.g., Doepke and Schneider (2006) and Auclert (2017)), the incidence of unemployment (e.g.,Carpenter and Rodgers III (2004)), the income composition channel (e.g., Coibion et al. (2017)) and cash holdings heterogeneity (e.g., Albanesi (2007)). In this paper, we identify a novel set of earnings and expenditure channels that emerge when production sectors are heterogeneous. While many dimensions of sectoral heterogeneity can give rise to these channels, we investigate them in the presence of heterogeneity in price rigidities across sectors. Price stickiness is the key source of monetary non-neutrality in NewKeynesian models and it is known to be heterogeneous across sectors (Nakamura and Steinsson (2008) and Pasten et al. (2016)). Our paper investigates the implications of heterogeneous price rigidities for the distributional and aggregate effects of monetary policy.

Given that price rigidity is a key transmission channel of monetary policy shocks, a household will be more affected by monetary policy if they work in a sector with rigid prices (earnings channel) or if they have high spending shares in sectors with rigid prices (expenditure channel). We characterize this intuition formally using a simple yet flexible framework building on Werning (2015). We show analytically that sectoral heterogeneity gives rise to a set of earnings and expenditure channels which, to the best of our knowledge, have not been examined in previous work. Although our theoretical results apply in any model featuring heterogeneous responses of sectors to monetary policy, empirically we focus on heterogeneity arising from differences in price rigidities across sectors.

Next, we build a new dataset to document the extent to which different education groups households with and without a college degree - are exposed to these novel expenditure and earnings channels. Our dataset brings together information on price rigidities, spending and payroll across detailed industries, covering the entire economy excluding shelter. To measure price rigidities across sectors, we rely on the data made publicly available by Nakamura and Steinsson (2008) for final goods and by Pasten et al. (2016) for intermediates. We obtain data on college spending shares from the Consumer Expenditure Survey (CEX) and on industry college payroll shares from the American Community Survey (ACS).

We find that prices are more rigid in product categories selling to more educated households as well as employing more educated households. Specifically, there is a strong negative correlation between the frequency of price adjustments in a product category and both the share of sales to college graduates (expenditure channel) and the share of payroll to college graduates (earnings channel). We find that a one percentage point increase in the frequency of price changes in an industry is associated with a 93.30 basis points fall in the share of payroll to college graduates ( 98.23 basis points when accounting for intermediates), as well as with a 21.98 decline in the share of sales to college graduates. These patterns are robust to the exclusion of sales as well as to the exclusion of "outlier" product categories with a particularly high frequency of price adjustment. Thus, college graduates are more exposed to both the earnings and expenditure channels of monetary policy. Quantitatively, the reduced-form patterns suggest that the earnings channel should dominate. 
Furthermore, we document a potentially important interaction between these two channels. We find that product categories with a high spending share fom college graduates also tend to have a higher payroll share to college graduates. In other words, the economy is "segregated": college graduates tend to buy from other college graduates. As a result, a monetary policy shock can start a feedback loop: college graduates are initially more responsive to the shock (given the earnings and expenditure channels), then their additional spending and labor supply generate general equilibrium effects that disproportionately benefit college graduates (given the interaction between the earnings and expenditure channels).

Our final reduced-form finding links structural change to price rigidities. Services feature a much higher degree of price rigidity than industries producing goods (e.g., Nakamura and Steinsson (2008) and Pasten et al. (2016)). Given that services account for an increasing share of both expenditures and payroll over time (e.g., Comin et al. (2018), the effective degree of price rigidities in the U.S. economy increases over time. Empirically, we find that price rigidities are about 40\% higher today than in 1950 because of structural change.

We quantify the implications of these new stylized facts for the distributional and aggregate effects of monetary policy using a multi-sector Heterogeneous Agent New Keynesian model. The intuition for this quantitative exercise is as follows: (1) NK models predict that sectors with more rigid prices experience less deflation and a bigger output gap in response to monetary policy tightening; (2) as a result, more educated households suffer more from monetary policy tightening: their preferred goods become relatively more expensive and the sectors in which they work have a stronger labor demand contraction; (3) because of a feedback loop via the consumption of more educated households, the demand for goods in more rigid sectors falls even more; (4) the general equilibrium effect on aggregate output is ambiguous. ${ }^{1}$

Using this model, we find that the consumption of college-educated households is $22 \%$ more sensitive to monetary policy shock, compared to households without a college degree. In addition, we find that the aggregate real effect of a $100 \mathrm{bp}$ monetary policy tightening shock is $5 \%$ stronger than absent heterogeneous price rigidities.

In ongoing work, we are considering alternative conterfactual shocks to better understand the implications of heterogeneous price rigidities for monetary policy. First, we quantify the impact of structural change for monetary policy (i.e., the fact that services, which are characterized by high price rigidity, account for an increasing share of total spending and total payroll). Second, we examine the impact of the secular rise in inequality. Finally, we benchmark the distributional effects from the expenditure and earnings channel to those induced by the saver-debtor channel, which has received much more attention in the existing literature (e.g., Doepke and Schneider (2006), Auclert (2017)).

In an independent and contemporaneous paper, Cravino et al. (2018) also study the implications of heterogeneous price rigidities for monetary policy. They focus on heterogeneity in price stickiness across the income distribution (the expenditure channel); contrary to us, they do not investigate the relationship between skill intensity and rigidities across sectors (the earnings channel) and they do not investigate the interaction between the earnings and expenditure channels. We view their analysis as

\footnotetext{
${ }^{1}$ In this draft, the model and calibration are based on an economy with only 2 sectors; we are developing a multi-sector version of the model in ongoing work.
} 
complementary to ours because they document patterns for detailed income groups, while we focus on broader education groups. We focus on education groups because it allows us to study both the expenditure and earnings channels and because education is a good proxy for permanent income.

The remainder of this paper is organized as follows. Section 2 presents our analytical framework to characterize the earnings and expenditure channels in the presence of sectoral heterogeneity. Section 2 presents the data and summary statistics. Section 3 reports our new reduced-form evidence on the expenditure and earnings channels of monetary policy arising from heterogeneous price rigidities across sectors. Section 4 develops the quantitative New Keynesian model and Section 5 reports the calibration results.

\section{Earnings and expenditure channels in the presence of sectoral hetero- geneity}

In this section, we identify and characterize analytically a new set of earnings and expenditure channels of monetary policy that emerge in the presence of sectoral heterogeneity. We do so using a simple yet flexible theoretical framework. Our model focuses on the demand side and households' consumption and savings decisions in the spirit of Werning (2015).

Our setting is as follows. Consider an economy with a finite number of household types, $i \in I$, each of which has mass $\mu_{i}$. There are two production sectors, $s \in\{A, B\}$, and household $i$ is exposed to these sectors differently in terms of both earnings and expenditures. The model has two periods, with $t=1,2$. We start with a perfect-foresight benchmark.

\subsection{Demand side}

Household preferences are standard and given by

$$
\sum_{t} \beta^{t-1} U\left(c_{i, t}\right)
$$

In particular, each household has the same preference structure. We abstract from labor disutility for now and assume that all households supply the same amount of labor. The household consumption basket is CES and can be written as

$$
c_{i, t}=\left(c_{i, t}^{A}\right)^{1-\alpha^{i}}\left(c_{i, t}^{B}\right)^{\alpha^{i}},
$$

where $c_{i, t}^{S}$ denotes consumption by a household of type $i$ of the consumption good produced in sector s. Sectoral consumption goods in turn consist of a continuum of intermediate inputs. Household $i^{\prime}$ s expenditure shares in sectors $A$ and $B$ are given, respectively, by $1-\alpha^{i}$ and $\alpha^{i}$. As a result of heterogeneity in these expenditure shares, households are exposed to the two sectors to varying degrees via an expenditure channel.

Our focus in this simple baseline model is on the demand side, and in particular on the consumption-savings decisions of households. We abstract almost entirely from the details of the supply side. We assume that there are two production sectors and the only source of sectoral heterogeneity is the degree of price stickiness. In particular, we think of sector $A$ as a rigid-price sector and 
sector $B$ as a flexible-price sector. As a result, shifts in the two sectors' marginal cost curves will lead to changes in the relative price of the two consumption goods. We define the relative price between the consumption good produced in sectors $A$ and $B$,

$$
p_{t}=\frac{P_{t}^{B}}{P_{t}^{A}}
$$

where $P_{t}^{s}$ is the producer price index (PPI) in sector $s$. The relative price will be a key variable of interest to understand how households' consumption-savings decisions respond to a monetary policy shock.

Given our focus on the demand side, we assume a reduced form specification for labor earnings and firms' profit rebates. In particular, household $i$ 's total income sourced from sector $s$ in period $t$ is given by $\gamma_{i}^{s}\left(Y_{t}^{s}\right)$. This modeling choice allows us to zoom in on the channels that will be most important for our quantitative analysis in later sections.

In this section, we also abstract from ad-hoc borrowing constraints so that we can collapse households' flow budget constraints into a single inter-temporal budget constraint. We write this budget constraint as

$$
c_{i, 1}^{A}+\frac{c_{i, 2}^{A}}{R}+p_{1} c_{i, 1}^{B}+p_{2} \frac{c_{i, 2}^{B}}{R}=\gamma^{i}\left(Y_{1}^{A}\right)+\frac{\gamma^{i}\left(Y_{2}^{A}\right)}{R}+p_{1} \gamma^{i}\left(Y_{1}^{B}\right)+p_{2} \frac{\gamma^{i}\left(Y_{2}^{B}\right)}{R}+\frac{b_{i, 1}}{\pi_{1}^{A}} .
$$

We have used sector $A^{\prime}$ 's PPI as the numeraire here as we will do throughout. We denote by $R=\frac{1+i_{2}}{1+\pi_{2}^{A}}$ the real interest rate between periods 1 and 2, and we assume that bonds pay out in units of sector $A^{\prime}$ s PPI. This is simply a numeraire normalization. In other words, we define the nominal bond position of household $i$ as $B_{i, t}=P_{t-1}^{A} b_{i, t}$. Finally, we normalize the initial net nominal interest rate to 0 . Realized inflation in period 1 , denotedy in gross terms by $\pi_{1}^{A}$ here, therefore directly affects the real value of households' initial nominal bond positions.

The price index for household $i^{\prime}$ s consumption bundle, to which we will refer as household $i^{\prime}$ s consumer price index (CPI), can be written as

$$
P_{i, t}=\left(P_{t}^{A}\right)^{1-\alpha^{i}}\left(P_{t}^{B}\right)^{\alpha^{i}}
$$

Households' consumption shares are then given by the standard formulas given our assumption on the Cobb-Douglas structure of the consumption basket

$$
\begin{aligned}
& P_{t}^{A} c_{i, t}^{A}=\left(1-\alpha^{i}\right) P_{i, t} c_{i, t} \\
& P_{t}^{B} c_{i, t}^{B}=\alpha^{i} P_{i, t} c_{i, t} .
\end{aligned}
$$

We can therefore rewrite household $i$ 's budget constraint in terms of the aggregate consumption bundle $c_{i, t}$. We have

$$
p_{1}^{\alpha^{i}} c_{i, 1}+\frac{1}{R} p_{2}^{\alpha^{i}} c_{i, 2}=\gamma^{i}\left(Y_{1}^{A}\right)+\frac{1}{R} \gamma^{i}\left(Y_{2}^{A}\right)+p_{1} \gamma^{i}\left(Y_{1}^{B}\right)+p_{2} \frac{1}{R} \gamma^{i}\left(Y_{2}^{B}\right)+\frac{b_{i, 1}}{1+\pi_{1}^{A}}
$$


Households' two-period consumption-savings problem is then to maximize (1) subject to the budget constraint (4). The first-order conditions give rise to the Euler equation

$$
U^{\prime}\left(c_{i, 1}\right)=\beta R U^{\prime}\left(c_{i, 2}\right)\left(\frac{p_{2}}{p_{1}}\right)^{-\alpha^{i}},
$$

which features relative price inflation. In particular, we see that the household's marginal rate of inter-temporal substitution is given by

$$
R\left(\frac{p_{2}}{p_{1}}\right)^{-\alpha^{i}}
$$

because bonds do not pay out in the price index of household $i$ 's consumption bundle. In other words, what matters for household $i$ 's consumption-savings decision is inflation in in the price of $i^{\prime}$ s consumption bundle, $P_{i, t}$, which we call the CPI of household $i$.

\subsection{Market clearing and aggregation}

Since we abstract entirely from the details of the supply side, the key market in this stylized economy is the goods market. Goods market clearing is given by

$$
Y_{t}^{s}=C_{t}^{s}
$$

We use this market clearing condition to think about the response of aggregate demand to monetary policy by tracing its effects on household consumption. This approach is in the spirit of Werning (2015).

To ensure that aggregate consumption and aggregate income coincide, we require

$$
\sum_{i} \mu_{i} \gamma_{i}\left(Y_{t}^{s}\right)=Y_{t}^{s}
$$

so that earnings distributed to households add, in fact, to aggregate income. Similarly, bond markets must clear, so that

$$
\sum_{i} \mu_{i} b_{i, t}=0
$$

Aggregation. We now discuss aggregation in our economy. We define aggregate consumption as

$$
C_{t}=\sum_{i} \mu_{i} c_{i, t}
$$

For sectoral consumption, we have

$$
C_{t}^{A}=\sum_{i}\left[\mu_{i}\left(1-\alpha^{i}\right) p_{t}^{\alpha^{i}} c_{i, t}\right]
$$

and similarly for sector $B$. 


\subsection{Monetary policy transmission}

To investigate the implications of sectoral heterogeneity, we now investigate the transmission of a monetary policy shock through this economy. As in Auclert (2017), we conjecture an aggregate perturbation which approximates a monetary policy shock in a class of New Keynesian models that share the details of our demand side. Consider a change in $R$, driven by a change in the nominal interest rate. As in any NK model, the assumption that monetary policy has no long-term effects on output represents a terminal condition for the dynamic IS equation. Here, the situation is similar and we simply assume that there are terminal conditions pinning down $Y_{2}^{A}$ and $Y_{2}^{B}$. Production in period 1 responds relative to these terminal values. In this sense, we consider period 2 to be the long run. Moreover, we restrict our attention to a perturbation with $\pi_{2}^{s}=0$ and $p_{2}=p_{1}=p$ for simplicity. In a one-sector NK model, it would be exactly true that prices remain unchanged in period 2. In summary, therefore, we consider the perturbation

$$
\left\{d R, d Y_{1}^{A}, d Y_{1}^{B}, d p, d \pi^{A}\right\}
$$

where we need to consider $d \pi^{A}$ explicitly to pin down the revaluation effects on nominal net worth. In other words, $d p$ and $d \pi^{A}$ together give us the evolution of all producer and consumer prices in the economy. Finally, we will assume that household preferences over consumption are CRRA, and we make a simplifying assumption on the structure of earnings heterogeneity. In particular, $\gamma^{i}\left(Y_{t}^{s}\right)=\gamma^{i} Y_{t}^{s}$.

Going forward, we define the marginal propensity to consume as

$$
M P C_{i, 1} \equiv \frac{\partial}{\partial y_{i}} p^{\alpha^{i}} c_{i, 1}
$$

where $y_{i}$ is the net present value of household $i$ 's lifetime wealth and earnings. Our definition of marginal propensity to consume here makes a relative price adjustment because we follow the convention that $y_{i}$ is counted in units of sector $A^{\prime}$ s PPI. We follow this convention throughout, taking sector $A^{\prime}$ 's PPI effectively as our numeraire. As a result, the relative price adjustment here is needed because the effective consumer price index of household $i$ differs from sector $A$ 's PPI depending on $i$ 's preference for sector B's goods, given by $\alpha^{i}$. The marginal propensity to save is then given by $M P S_{i, 1}=1-M P C_{i, 1}$. This equation holds true as long as we abstract from households' behavioral labor supply response as we do here. Under CRRA, once we define MPC as above to account for the right price index, we have

$$
M P C_{i, 1}\left[1+\frac{1}{R} \frac{c_{i, 2}}{c_{i, 1}}\right]=1
$$

We can now record our first result.

Proposition 1. In response to our proposed aggregate perturbation, household i's behavioral consumption 
response can be decomposed into

$$
\begin{aligned}
d c_{i, 1}= & -\overbrace{\frac{1}{\gamma} M P S_{i, 1} c_{i, 1} \frac{d R}{R}}^{\text {Substitution effect }}+M P C_{i, 1}\{\overbrace{b_{i, 2} \frac{d R}{R}}^{\text {Interest rate exposure }}-\overbrace{\frac{b_{i, 1} \frac{d P^{A}}{\pi^{A}}}{P A}}^{\text {Bond revaluation }} \\
& +\underbrace{\gamma_{i}^{A} d Y_{1}^{A}+p \gamma_{i}^{B} d Y_{1}^{B}}_{\text {Heterogeneous earnings channel }}+\underbrace{\gamma_{i}^{B} p\left(Y_{1}^{B}+\frac{1}{R} Y_{2}^{B}\right)}_{\text {Relative price effect on real earnings }} \quad \underbrace{\frac{d p}{p}-\alpha^{i} p^{\alpha^{i}}\left(c_{i, 1}+\frac{1}{R} c_{i, 2}\right)}_{\text {Relative price effect on real expenditures }} \frac{d p}{p} .
\end{aligned}
$$

The derivation of Proposition 1 is in the spirit of Auclert (2017), and the proof is given in Appendix A.1. Unlike his paper, our focus is on the implications of sectoral heterogeneity on the transmission of monetary policy, especially in the context of heterogeneous household exposure to the different production sectors of the economy. These new forces are encapsulated by the three novel terms in the second line of equation (11). Before discussing each of these new channels in turn, it is instructive to note that only the first term of equation (11) is a substitution effect - in this case, the inter-temporal substitution effect. All other terms are wealth effects. We have written Proposition 1 in terms of $d c_{i, 1}$, a change in real expenditures on household $i$ 's consumption basket. Since we are recording our results at the basket level, equation (11) naturally does not feature substitution effects between sectoral goods. When we instead write this equation in terms of a change in sectoral expenditures, $d c_{i, 1}^{s}$, as we do below in equation (13), a sectoral substitution effect emerges.

The first of our three novel terms is the heterogeneous earnings channel. Unlike in the one-sector analogue of our model, where household income is proportional to aggregate income, the earnings channel of monetary policy now works through changes in sectoral income, and each household $i$ is affected proportional to its exposure to the different sectors, given by $\gamma_{i}^{s}$. In other words, the households most affected by the earnings channel of monetary policy are the ones whose earnings are tied predominantly to sectors that are sensitive to monetary policy. In our model, these are rigid-price sectors in which adjustment cannot go through prices and therefore goes through output.

The second novel term in equation (11) that speaks to the earnings channel of monetary policy is the relative price effect on real earnings. This is a more subtle way in which monetary policy affects the real earnings of households. Recall that our convention is to denote real earnings in units of sector $A^{\prime}$ 's PPI. If household $i$ 's income is tied to sector $B$ and the relative price changes, then, for a given amount of income generated in sector $B$, the real value of that income changes in proportion to the relative price change. The first and second channels comprise what we call the earnings channel of monetary policy.

Finally, our model features a novel expenditure channel of monetary policy, which corresponds to the relative price effect on real expenditures term in equation (11). As the relative price of sectoral goods changes in response to a monetary policy shock, the real price of a real unit of household $i^{\prime} s$ consumption basket changes. The strength of this effect is proportional to household $i$ 's expenditure share, $\alpha^{i}$. A monetary policy tightening, for example, leads to a steeper fall in prices in the flexible-price sector $B$ so that the relative price $p$ falls. Households with a large expenditure share on sector $B^{\prime}$ s goods, a large $\alpha^{i}$, therefore experience a windfall. This positive wealth effect leads to an increase in overall consumption expenditures. 
In our representation of Proposition 1 the expenditure channel of monetary policy comprises only a wealth effect because we wrote equation (11) at the basket expenditures level. In equation (13) below, we express household $i$ 's behavioral response in terms of expenditures on sector $A$ 's goods. We consider the novel sectoral substitution effect that emerges also part of the overall expenditure channel of monetary policy.

To characterize the response of aggregate demand, we can simply aggregate over individual households' consumption responses. That is, the change of aggregate demand in period 1 can be written as $d Y_{1}=\mathbb{E}_{I}\left(\mu_{i} d c_{i, t}\right)$. We can now record our second important result, for which we assume a uniform mass of households, with $\mu_{i}=\mu$.

Proposition 2. In response to our proposed aggregate perturbation, the change in aggregate demand can be decomposed as

$$
\begin{aligned}
d Y_{1}= & {\left[\operatorname{Cov}_{I}\left(M P C_{i, 1}, \mu b_{i, 2}\right)-\frac{1}{\gamma} \mu \mathbb{E}_{I}\left(M P S_{i, 1} C_{i, 1}\right)\right] \frac{d R}{R}-\operatorname{Cov}_{I}\left(M P C_{i, 1} \frac{\mu b_{i, 1}}{\pi^{A}}\right) \frac{d P^{A}}{P^{A}} } \\
& +\underbrace{\sum_{s} \frac{P_{t}^{s}}{P_{t}^{A}}\left(\mathbb{E}_{I}\left(M P C_{i, 1}\right)+\mu \operatorname{Cov}_{I}\left(M P C_{i, 1}, \gamma_{i}^{s}\right)\right) d Y_{1}^{s}}_{\text {Heterogeneous earnings effect }} \\
& +\sum_{t} \frac{1}{R^{t-1}}[\underbrace{p\left(\mathbb{E}_{I}\left(M P C_{i, 1}\right)+\mu \operatorname{Cov}_{I}\left(M P C_{i, 1}, \gamma_{i}^{B}\right)\right) Y_{t}^{B}}_{\text {Relative price effect on earnings }}-\underbrace{\mathbb{E}_{I} \mu\left(M P C_{i, 1} \alpha^{i} p^{\alpha^{i}} c_{i, t}\right)}_{\text {Relative price effect on expenditures }}] \frac{d p}{p} .
\end{aligned}
$$

As before, the heterogeneous earnings effect and the relative price effect on earnings together comprise the earnings channel of monetary policy. The relative price effect on expenditures comprises the expenditures channel of monetary policy. The first row of equation (12) features standard channels of monetary policy transmission known from Auclert (2017) and other papers. These are, in order, the unhedged interest rate exposure, the inter-temporal substitution, and the unhedged inflation exposure channels.

Finally, we want to find the aggregate sectoral demand response, $d Y_{1}^{s}$. Then we can write household $i$ 's behavioral demand response for consumption expenditures on good $A$ as

$$
\begin{aligned}
d c_{i, 1}^{A}= & \overbrace{\alpha^{i} c_{i, 1}^{A} \frac{d p}{p}}^{\text {Sectoral substitution channel }}-\frac{1}{\gamma} M P S_{i, 1} c_{i, 1}^{A} \frac{d R}{R}+\left(1-\alpha^{i}\right) p_{1}^{\alpha^{i}} M P C_{i, 1}^{A}\left\{b_{i, 2} \frac{d R}{R}+\gamma_{i}^{A} d Y_{1}^{A}+p \gamma_{i}^{B} d Y_{1}^{B}\right. \\
& \left.+\gamma_{i}^{B} p\left(Y_{1}^{B}+\frac{1}{R} Y_{2}^{B}\right) \frac{d p}{p}-\alpha^{i} p^{\alpha^{i}}\left(c_{i, 1}+\frac{1}{R} c_{i, 2}\right) \frac{d p}{p}-\frac{b_{i, 1}}{\pi^{A}} \frac{d P^{A}}{P^{A}}\right\} .
\end{aligned}
$$

The main difference between this and equation (13), which is written at the consumption basket level, is that a novel sectoral substitution channel emerges. We can further underscore this relationship by rewriting equation (13) as

$$
d c_{i, 1}^{A}=\overbrace{\alpha^{i} c_{i, 1}^{A} \frac{d p}{p}}^{\text {Sectoral substitution channel }}+\left(1-\alpha^{i}\right) p^{\alpha^{i}} d c_{i, 1} .
$$


This substitution channel is part of the overall expenditure channel of monetary policy, which comprises a substitution effect and a wealth effect. The earnings channel, on the other hand, comprises two distinct wealth but no substitution effects.

Aggregating over equation (13), we can record the following result.

Proposition 3. In response to our proposed aggregate perturbation, the change in sectoral demand in sector A can be decomposed as

$$
d Y_{1}^{A}=\mathbb{E}_{I}\left[\mu\left(1-\alpha^{i}\right) p_{1}^{\alpha^{i}}\right] d Y_{1}+\mathbb{E}_{I}\left[\mu \alpha^{i}\left(1-\alpha^{i}\right) p^{\alpha^{i}} c_{i, 1}\right] \frac{d p}{p}+\mu \operatorname{Cov}_{I}\left[\left(1-\alpha^{i}\right) p_{1}^{\alpha^{i}}, d c_{i, 1}\right] .
$$

Proposition 3 formalizes at the aggregate level what we have already noted at the household level. When expressed in terms of sectoral expenditures, a sectoral substitution channel emerges which is also part of the overall expenditure channel of monetary policy.

\section{Data Sources and Summary Statistics}

In this section, we describe the data sources, define the key variables we use in the analysis, and present summary statistics.

\subsection{Data Sources and Variable Definitions}

Price rigidities across industries. To measure price rigidities across industries, we rely on two data sources. For final consumption industries, we use the data made publicly available by Nakamura and Steinsson (2008). They estimated the frequency of price changes using the confidential micro-level price data underlying the the Consumer Price Index (CPI) computed by the U.S. Bureau of Labor Statistics. The CPI measures changes in selling prices from the perspective of consumers, recording prices charged for a particular product at a particular store. Nakamura and Steinsson (2008)'s estimates of the frequency of price changes are available for 272 product categories, called "Entry-Level Item" (ELI) categories. "Carbonated Drinks", "Washers and dryers" and "Funeral expenses" are examples of ELIs. This dataset covers approximately $70 \%$ of consumer expenditures; in particular, it does not cover shelter.

The frequency of price adjustment is defined as the ratio of the number of price changes to the number of periods for which a product is observed (depending on the product category, a period is one or two months). Nakamura and Steinsson (2008) report two measures of the frequency of price adjustments, with and without sales, which we use alternatively. Their publicly available estimates are based on period 1998-2005, but their paper reports that the patterns across ELIs are similar for 1988-1997. Therefore, we view the estimates from Nakamura and Steinsson (2008) as good proxies for permanent differences in price rigidities across industries over time. Because their data covers most of consumer expenditures, it is ideal to investigate the expenditure channel.

Furthermore, to measure price rigidities for both final consumption and intermediates industries, we rely on data from Pasten et al. (2016). They measure the frequency of price adjustments at the 
level of 754 industries (defined by 6-digits NAICS codes) using the data underlying the Producer Price Index (PPI) from the U.S. Bureau of Labor Statistics. The PPI measures changes in selling prices from the perspective of producers and covers all industrial and service sectors, including the product of intermediate inputs such as mining or semiconductors. The estimates of Pasten et al. (2016) pull together the PPI data from 2005 to 2011; related work by D'Acunto et al. (2018) show that the patterns of price rigidities across industries were similar in an earlier period, therefore we view these estimates as capturing permanent differences across sectors. To document the earnings channel, we use the datasets from Nakamura and Steinsson (2008) and Pasten et al. (2016) in combination.

Worker characteristics. We use the American Community Survey (ACS) to measure worker characteristics across industries. The ACS is a survey administered by the U.S. Census Bureau and answered by a random $1 \%$ sample of the U.S. population every year. The dataset is made available by IPUMS (Ruggles et al. (2015)) and provides rich information for all survey respondents, including industry, education, occupation and income. In particular, the ACS provides consistent industry identifiers for 320 industries in the private sector from 2000 to 2015.

For each industry, we measure the average payroll share of college graduates during the sample period. In robustness checks, we repeat the analysis across subsamples of a few years. While we focus on patterns across education group, for robustness we select all respondents employed in the private sector and aggregate their annual labor income by industry to measure differences in exposure to difference sectors by income groups.

Consumer characteristics. To measure the characteristics of consumers across industries, we use the Consumer Expenditure Survey (CEX). The CEX is a survey conducted by the U.S. Bureau of Labor Statistics. The survey respondent report their consumption expenditures for the full consumption basket of goods and services, across 650 detailed categories called "UCCs". The CEX is made of two separate surveys, which we use in combination: the "interview survey" covers the full range of expenditures, while the "diary survey" provides more detailed information for certain product categories like food and clothing.

The CEX tracks many household characteristics. We focus on spending patterns by education groups, depending on whether the household head has a college degree or not. In robustness check, we also consider bins of household income before tax. For the baseline results, we combine all CEX data from 2004 to 2015. In robustness check, we report the patterns across subsamples of a few years.

Expenditure on housing services requires special treatment, because the CEX spending categories include rents and mortgage interest but not mortgage principal payments. To address this limitation, we follow Borusyak and Jaravel (2017) and add imputed rents based on an addendum section of the interview survey, which provide information on the self-reported rental value of owned property. We also borrow income elasticity estimates for each UCC from Borusyak and Jaravel (2017). ${ }^{2}$

\footnotetext{
${ }^{2}$ Borusyak and Jaravel (2017) split households in the CEX sample into 11 bins by the reported pre-tax household income and compute consumption shares across UCCs for each income bin separately. For each spending category, they estimate the income semi-elasticity by regressing spending shares of an income group for a given UCC on the log of total expenditure for this income group.
} 
Linked datasets. We build three linked datasets for our analysis of the earnings and expenditure channels. First, we merge the price rigidity data from Nakamura and Steinsson (2008) (at the ELI level) to the earnings data from the ACS (at the industry level). Because the ACS industries are more aggregated than the ELI product categories, we implement a "many-to-one" merge from ELI to ACS industries. We implement the match by hand. We average the price frequency adjustments across all ELIs linked to the same ACS industry using ELI spending weights provided by Nakamura and Steinsson (2008). Our linked dataset has 94 ACS industries covering all final consumption goods and services, except shelter. We use this dataset, which we refer to as the CPI-ACS sample, to examine the earnings channel across final consumption industries.

Second, we match the price rigidity data from Pasten et al. (2016) (at the 6-digit NAICS level) to ACS industries. Again, because the ACS industries are more aggregated than 6-digit NAICS industries, this merge is "many-to-one". We use crosswalks provided by the Census and hand matching to link all industries; we take a simple average of the price frequency adjustments across all 6-digit NAICS industries matched to same ACS industry. Our linked dataset covers 169 ACS industries: we use this dataset to examine the earnings channel accounting for intermediates production. We refer to this dataset as the PPI-ACS sample in the remainder of this paper.

Finally, to document the expenditure channel, we merge the CEX to the ELI product categories. Because the 650 UCCs from the CEX are more detailed than the 272 ELIs from Nakamura and Steinsson (2008), we implement a "many-to-one" merge from UCCs to ELIs. We sum up all spending patterns for all UCCs linked to the same ELI. Because a few ELIs do not find a linked UCC, our final dataset covers 254 ELIs. We refer to it as this CPI-CEX sample.

\subsection{Summary Statistics}

Table 1 presents summary statistics for our three linked datasets. Panel A focuses on the patterns for the CPI-ACS sample, documenting worker characteristics and price rigidities across 94 final consumption industries. All statistics are reported using total payroll weights. The first row of this panel shows that the average frequency of price changes across industries is $16.51 \%$, with a larger standard deviation (14.07\%). The distribution of price rigidities across industries is quite skewed: the 95th percentile (37.95\%) is almost four times larger than the median $(10.08 \%)$.

The second row reports the patterns when excluding sales from the measurement of the frequency of price adjustments. The average price adjustment frequency falls to $11.29 \%$ while the standard deviation remains large (12.47\%). Compared to the price frequency adjustment taking sales into account, the median falls by a factor of almost two, while the 95th percentile remains similar. Because the price frequency adjustment distribution is so skewed, it will be important to check that the patterns we document are robust to the exclusion of observations in the tail of the price change distribution, which are likely to be estimated with considerable measurement error.

The third and fourth row of Panel A of Table 1 characterize skill intensity across industries. The average payroll share to college graduates is $66.63 \%$, with considerable variation across industries: the standard deviation is $19.37 \%$. Similar patterns hold when using an alternative proxy for skill intensity, the share of payroll to workers earning above $\$ 60,000$ (which approximately equal to median income 
during the sample period).

Panel B of Table 1 reports summary statistics for the PPI-ACS sample, using payroll weights. This sample documents worker characteristics and price rigidities across 169 industries, accounting for industries producing intermediate inputs in addition to industries producing final products. The first row shows that the frequency of price changes (taking into account all price changes) is quite similar in this sample to the patterns in the CPI-ACS sample. The distribution of price rigidities appears to be even more skewed.

The second of third row report skill intensity across industries using the payroll shares to college graduates and workers earning above $\$ 60,000$. Here as well, there patterns are similar to the CPI-ACS sample: there is substantial heterogeneity in skill intensity across industries.

Panel C of Table 1 shows summary statistics for the CPI-CEX sample used to investigate the expenditure channel. All statistics are reported using spending weights in this panel, across 254 ELI product categories. The first row shows that the average frequency of price changes (taking into account all price changes) is $26.19 \%$. The contrast with the first row of Panel A is interesting: using payroll weights instead of spending weights, the average price adjustment frequency is significantly lower $(16.51 \%)$. As will become more apparent in Section 3, this difference has much to do with differences in price rigidities across goods and services. Prices tend to be much more rigid in services and consumers' spending share on services tends to be lower than workers' payroll share from service industries (because many goods are imported). As a result, the average price frequency adjustment is lower from the perspective of workers, compared with consumers.

The second row of Panel $\mathrm{C}$ shows that the frequency of price adjustment falls when sales are excluded. The average frequency becomes $20.60 \%$, but the standard deviation remain similar $(25.59 \%)$. These numbers are very close to the statistics reported in Nakamura and Steinsson (2008).

The third and fourth rows of Panel $\mathrm{C}$ report spending patterns depending on education and income. College graduates account for about $41.01 \%$ of total sales on average, with a substantial standard deviation across industries (11.02\%). The reason why college graduates account for a smaller share of sales than of total payroll (cf. panels A and B) is simply that the CEX data considers spending from all households, including those out of the labor force, while the skill-intensity patterns from the ACS data are by definition based on the working-age population alone. The fourth row shows that there is also substantial heterogeneity across product categories in the share of sales to households earning above $\$ 60,000$.

In sum, the summary statistics for our three linked datasets show that there is substantial variation in price rigidities, worker characteristics and consumer characteristics across industries. Next, we document correlations between these patterns to provide reduced-form evidence on the potential strengths of the earnings and expenditure channels.

\section{Reduced-Form Evidence on the Earnings and Expenditure Channels}

If workers with or without a college degree tend to work in sectors with systematically different levels of price rigidities, monetary policy could have distributional effects via an "earnings channel". 
Likewise, if households of different education levels systematically spend on product categories with a different average level of price rigidity, then there could be an important "expenditure channel" of monetary policy. Finally, these two channels could interact to the extent that college-educated households tend to predominantly purchase goods or services produced by college-educated workers. We examine the empirical relevance of these potential channels in Section 3.1. Then, we examine which sectors, such as goods vs. services, drive heterogeneity in price rigidities.

\subsection{Earnings and Expenditure Channels across Education Groups}

Earnings channel. Figure 1 reports our key finding on the earnings side: product categories that have a smaller frequency of price adjustment (i.e., that are more rigid) have a higher payroll share to college graduates. Panel A of Figure 1 focuses on final consumption industries only (CPI-ACS sample), while Panel B accounts for intermediate inputs (PPI-ACS sample).

The scatter plots demonstrate non-parametrically the robustness of the relationships between price rigidity and the share of payroll to college graduates. The patterns are not driven by any single industry and, rather, reflect a relationship that appears to be pervasive. This reduced-form evidence indicates that college graduates should be more affected by monetary policy, because they tend to work in sectors that are more rigid.

Panels A and B of Table 1 documents the magnitude of the earnings channel across education groups. Panel A uses the CPI-ACS sample and investigates the relationship between the share of payroll to college graduates and the frequency of prices changes across specifications. All specifications use total payroll weights. Column (1) shows our preferred specification, which corresponds to Panel A of Figure 1 and excludes product categories in the top $5 \%$ of the price adjustment frequency distribution. We view these industries as outliers, for which the price adjustment frequency is likely to be mismeasured. The point estimate indicates that a 1 percentage point increase in the frequency of price changes is associated with a 93.30 basis points fall in the share of payroll to college graduates. In terms of standard deviations (from Table 1, Panel A), this implies that a one standard deviation (14.07 $\mathrm{pp}$ ) increase in the frequency of price changes is associated with a decline of 0.67 standard deviations $(=0.9330 * 14.07 / 19.37)$ in the share of payroll to college graduates.

Columns (2) to (6) of Panel A investigate the drivers of this relationship. Column (2) reports the relationship after controlling for fixed effects at the level of 18 consolidated industries (2-digit Naics codes). The relationship remains statistically significant conditional on these fixed effects, but the magnitude falls by about $50 \%$ relative to Column (1). This result indicates that about half of the earnings channel occurs within 2-digit Naics codes, while the other half arises within. Column (3) repeats the analysis in the full sample, keeping outlier industries with a very high frequency of price adjustments. With this specification as well, the patterns remain strong although the magnitude is slightly attenuated, with a point estimate of 55.05 basis points.

Columns (4) to (6) document the role of sales. In Column (4), without outlier industries and without sales, the coefficients fall to 61.16 basis points, indicating that about a third of the relationship reported in Column (1) can be attributed to the role of sales. Column (5) indicates that most of the 
relationship within 2-digit Naics industries is driven by sales, because the point estimate is no longer significant when sales are excluded. Finally, Column (6) shows that when keeping outlier industries and excluding sales, statistical significance for the earnings channel is lost, although the point estimate remains sizable in magnitude. Overall, Table A indicates that college graduates are more exposed to price rigidities and that this patterns is not overwhelmingly driven by broad groups of industries nor by sales.

Panel B of Table 1 continues the investigation of the earnings channel in the PPI-ACS sample, now accounting for industries producing intermediate inputs. All specifications use total payroll weights. Column (1) reports our preferred specification, corresponding to Panel B of Figure 1 and excluding outlier industries. According to the point estimate, a one percentage point increase in the frequency of price changes is associated with a 98.23 basis points fall in the share of payroll to college graduates. In terms of standard deviations (from Table 1, Panel B), this implies that a one standard deviation (15.70 pp) increase in the frequency of price changes is associated with a decline of 0.78 standard deviations $(=0.9823 * 15.70 / 19.60)$ in the share of payroll to college graduates. The patterns are therefore quantitatively very similar to the results from the CPI-ACS sample in Panel A.

Column (2) shows that most of this relationship occurs because of differences between 2-digit Naics industries, because statistical significance is lost when 2-digit Naics fixed effects are included in the specification. Column (3) reports that the coefficient falls by about two third when outlier industries are kept in the sample.

Overall, the patterns remain similar in the expanded PPI-ACS sample and a consistent picture emerges: college graduates are more exposed to monetary policy shock via the earnings channel.

Expenditure channel. Figure 2 reports our key finding on the expenditure side: product categories that have a smaller frequency of price adjustment (i.e., that are more rigid) also have a large share of sales to college graduates. The figure reports this relationship non-parametrically: each circle represent one ELI product category form the CPI-CEX sample. The relationship appears to be less steep than for the earnings channel but is nonetheless clear: college graduates are more exposed to monetary policy because they purchase relatively more from product categories with higher levels of price rigidity.

Panel C of Table 1 document the magnitude and drivers of this relationship. All specifications use total spending weights. Column (1) reports our preferred specification, excluding outlier industries in the top $5 \%$ of the distribution of the price adjustment frequency. The point estimate shows that a one percentage point increase in the frequency of price changes is associated with a 21.08 basis points fall in the share of sales to college graduates. The magnitude of the point estimate is thus about a fifth of the point estimate for the earnings channel. In terms of standard deviations (from Table 1, Panel C), this result implies that a one standard deviation ( $24.78 \mathrm{pp})$ increase in the frequency of price changes is associate with a fall of 0.47 standard deviation $(=24.78 * 0.2108 / 11.02)$ in the share of sales to college graduates.

Columns (2) to (6) investigate the role of broad expenditure categories, outlier industries and sales in these patterns. Column (2) repeats the specification with fixed effects for 8 broad expenditure categories defined by the Bureau of Labor Statistics, called major groups. The point estimate remains virtually identical to Column (1), indicating that the expenditure channel arises exclusively within 
broad expenditure categories, rather than across. In Column (3), outlier industries are included in the sample. The point estimate falls significantly (to -0.1256) but remain statistically significant.

Columns (4) to (6) report similar specifications when excluding sales from the measurement of the frequency of price changes. Columns (4)and (5) show that statistical significance is lost when sales are excluded. However, standard errors are large and we cannot reject the point estimates from Columns (1) and (2). In Column (6), when excluding sales and including outlier industries, the relationship becomes statistically significant again and comparable in magnitude to Column (3).

In sum, college graduates are more exposed to monetary policy through the expenditure channel. But this mechanism does not seem to be as strong as the earnings channel quantitatively, and sales appear to play a prominent role.

Interaction between the two channels. Figure 3 reports the key relationship characterizing the potential interaction between the earnings channel and the expenditure channel. To document this relationship, we match the information on expenditure shares from the CPI-CEX sample (avaliable at the level of ELIs) to the CPI-ACS sample (available at the level of ACS industries). Because there are more ELIs than ACS industries, we implement a "many-to-one" merge from ELI to ACS industries (using crosswalk we built to assemble the CPI-ACS dataset, as described in Section 2.1).

Figure 3 shows that product categories with a high spending share from college graduates tend to have a higher payroll share to college graduates. The relationship is depicted non-parametrically: each circle represents one ACS industry and the size of the circle indicates the weight of that industry in the overall relationship (using total payroll weights).

Because college graduates buy relatively more from other college graduates, there is room for an interaction effect between the expenditure and earnings channels of monetary policy. We use a New Keynesian model in the next section to assess the quantitative importance of each channel and of their interaction.

Robustness. Figures 4 and 5 assess the robustness of our findings on the earnings and expenditure channels of monetary policy. Figure 4 investigates robustness to variable definitions. Panels A and B of Figure 4 use an alternative measure of "consumer type", the income elasticity from Borusyak and Jaravel (2017), to investigate the robustness of the expenditure channel as well as of the interaction between the earnings and expenditure channel. These panels show that the relationships remain strong with this alternative measure. Furthermore, panel $\mathrm{C}$ shows that the expenditure channel continues to hold when using the spending share from households earning above $\$ 60,000 /$ year, instead of spending shares from college graduates.

Figure 5 documents the robustness of our findings across sample periods. Although our measures of price rigidities are not available over time, the earnings patterns from the ACS and the expenditure patterns from the CEX do vary over time. We therefore repeat the analysis by using the ACS and CEX datasets in various sub-periods of our full sample. Panel A of Figure 5 reports the results for the earnings channel in the CPI-ACS sample. In all four sub-periods, we find a negative relationship between price adjustment frequency and share of payroll to college graduates. Panel B repeats this exercise in the PPI-ACS sample and, likewise, finds that the patterns are very similar across all sub- 
periods. Finally, Panel C conducts the analysis across three sub-periods using CEX data: the patterns are stable. Thus, the earnings and expenditure channels are not driven by particular sub-periods of our data.

In unreported results available upon request, we examine price rigidities across the income distribution in a non-parametric way; we do so to gauge whether the patterns we document across education groups are consistent with broader trends across income groups. First, we compute average rigidities by bin of the income distribution (in ventiles, i.e. 5pp increments) using the PPI-ACS sample. In each bin of the income distribution we compute "exposure" to price rigidities via the earnings channel, defined as the average frequency of price adjustment with payroll weights. Whether all price changes are included or whether sales are excluded, we find a robust patterns: the average frequency of price adjustment is decreasing in income. This finding suggests that our results across education groups, our focus in this paper, reflect broader trends across the income distribution.

We then conduct a similar exercise for the expenditure channel, computing the average frequency of price adjustment across bins of the income distribution using income-group-specific spending shares across sectors in the CPI-CEX sample. As first shown in Cravino et al. (2018), the average price adjustment frequency is higher for the middle class,. However, we find that the relationship becomes flat once we exclude product categories in the top 5\% of the distribution of price adjustment frequency. It appears that the inverted-U relationship is in fact driven by a single expenditure class, motor fuel, which has a very high frequency of price adjustments and is predominantly consumed by the middle class. The patterns of price rigidities across the income distribution become flat once the "motor fuel" ELIs are excluded. ${ }^{3}$ This result suggests that our findings about the expenditure channel across education groups is consistent with a broader trend across the income distribution: the expenditure channel operates, but it appears to be weaker than the earnings channel.

\subsection{Earnings and Expenditure Channels across Sectors}

Goods and services. Figure 6 reports average price rigidities across goods and services. Panel A computes average price rigidities within goods and within services, using the price rigidity estimates from Nakamura and Steinsson (2008) and total spending by product category from CEX. A robust pattern emerges: the frequency of price adjustment is close to four times smaller for services than for goods. The difference is attenuated when sales are excluded, but prices within goods remain three times less rigid than for services.

Panel B repeats the analysis using payroll weights instead of expenditure weights. As previously, the payroll weights are obtained from the ACS. The difference in price rigidities between goods and services is smaller than with expenditure weights, but it remains very large. Including all price changes, the frequency of price adjustment is about 2.5 times larger for goods. Excluding sales, it remains approximately 1.5 times larger.

Finally, Panel $\mathrm{C}$ shows that with output value weights the patterns are very close to those with

\footnotetext{
${ }^{3}$ There are five such ELIs: "premium unleaded gasoline", "alternative motor fuels", "automotive diesel fuel", "regular unleaded gasoline", "mid-grade unleaded gasoline".
} 
expenditure weights from Panel A. Intuitively, the differences across weights come from the fact that import shares and capital intensity vary across sectors. But it is always the case that services are much more rigid than goods (consistent with Nakamura and Steinsson (2008), among others).

Patterns across susbectors. Figure 7 describes heterogeneity in price rigidities across 11 subsectors. The results are very similar with either expenditure weights (as in Panel A) or payroll weight (as in Panel B), regardless of whether all price changes are used whether sales are excluded. Certain sectors like agriculture, manufacturing have a particularly high frequency of price adjustment. Certain sectors within services, such as utilities and transportation, are also characterized by a high degree of price rigidities. But sectors like finance, education and entertainment substantially lower average rigidities within services.

The role of structural change. Figure 8 suggests that differences in rigidities across broad sectors of the economy can have important implications for monetary policy because of structural change. Panel A of Figure 8 depicts the secular fall in the expenditure share of goods (reproduced from Boppart (2014)). The expenditure share on goods decline from $60 \%$ in 1946 to $32 \%$ in 2000.

Panel B of Figure 8 shows that the secular fall in the spending share on goods implies a large fall in average price rigidities. Because services account for an increasing share of spending, the frequency of price adjustment was approximately 8 percentage points higher in 1950 than in 2010, that is to say about $40 \%$ higher. In ongoing work, we quantify the implications of structural change for monetary policy, accounting for the roles of both the expenditure and earnings channels.

\section{A quantitative model}

We present a New Keynesian model with heterogeneous households and two firm sectors. There are two household types, College and Non-College, each of which features rich within-type heterogeneity. In that sense, we substantially extend the heterogeneous agent New Keynesian (HANK) model proposed by Kaplan et al. (2017) along three dimensions: First, production sectors differ in their degree of price stickiness. Second, households of different education types have different preferences for the goods produced in different sectors. Finally, households of different education types work in different production sectors.

It is these three extensions to a standard HANK model that allow us to capture the novel facts we presented in the previous section. In particular, we will calibrate the model so that College-type households purchase and work relatively more in production sector $A$, which we will denote the rigid-price sector.

We take the HANK model proposed by Kaplan et al. (2017) rather than a standard NK model as our baseline model for two distinct reasons. First, a standard NK model with two household types features multiplicity in steady-state bond positions. Second, the effects of monetary policy in the standard NK model work through an inter-temporal substitution effect. In our model, indirect effects will play a much more important role. Since the novel facts we present in the previous section interact

primarily with these indirect channels of monetary policy, we cannot seriously study their implications 
in a model that largely shuts down these channels.

\subsection{Households}

The model is cast in continuous time. We index household types by $i \in\{C, N C\}$ for College and Non-College, respectively. The preferences of household type $i$ are standard and given by

$$
E \int_{0}^{\infty} e^{-\rho_{i} t} u\left(c_{i, t}, n_{i, t}^{s}\right) d t
$$

where the discount parameter $\rho_{i}$ is possibly type-specific. In all of our quantitative exercises below, we use a symmetric discount factor. We take preferences to be CRRA, so that

$$
u\left(c_{i, t}, n_{i, t}^{s}\right)=\frac{c_{i, t}^{1-\gamma}}{1-\gamma}-\sum_{s} \frac{\left(n_{i, t}^{s}\right)^{1+\phi}}{1+\phi} .
$$

Note that households of type $i$ work in both production sectors, $s \in\{A, B\}$. Given our current assumptions on preferences, each individual household will work some non-zero amount of time in each sector. This assumption is primarily made for tractability. We conjecture that the introduction of extensive margin labor supply responses would, if anything, amplify the key quantitative results we obtain below. ${ }^{4}$

Households consume a CES basket of goods given by

$$
c_{i, t}=\left[\left(1-\alpha^{i}\right)^{\frac{1}{\eta}}\left(c_{i, t}^{A}\right)^{\frac{\eta-1}{\eta}}+\left(\alpha^{i}\right)^{\frac{1}{\eta}}\left(c_{i, t}^{B}\right)^{\frac{\eta-1}{\eta}}\right]^{\frac{\eta}{\eta-1}},
$$

where $c_{i, t}^{s}$ denotes consumption by a household of type $i$ of the consumption good produced in sector s. $\eta$ is the elasticity of substitution between the goods produced in different sectors. To obtain the first of our two novel facts in our model, we allow different household types to have different preferences for goods produced in different sectors. This is captured here by $\alpha^{i}$.

Sectoral consumption goods are in turn given by

$$
c_{i, t}^{S}=\left(\int_{0}^{1} c_{i, t}^{S}(j)^{\frac{\epsilon-1}{\epsilon}} d j\right)^{\frac{\epsilon}{\epsilon-1}},
$$

where $s \in\{A, B\}$ and $j$ refers to the intermediate good producer $j$ in sector $s$. This yields the standard demand functions for sectoral goods

$$
\begin{aligned}
& c_{i, t}^{A}=\left(1-\alpha^{i}\right)\left(\frac{P_{t}^{A}}{P_{i, t}}\right)^{-\eta} c_{i, t} \\
& c_{i, t}^{B}=\alpha^{i}\left(\frac{P_{t}^{B}}{P_{i, t}}\right)^{-\eta} c_{i, t} .
\end{aligned}
$$

\footnotetext{
${ }^{4}$ In the quantitative section, we introduce a Poisson-switching process that we do not explicitly take into account here. In particular, we assume that there is some exogenous intensity at wich households of type $i$ transition to type - $i$. We think of this process as inter-generational transitions and calibrate the intensity parameter to match that data.
} 
where $P_{i, t}$ is the effective consumption price index faced by household type $i$. The sectoral producer price index is given by $P_{t}^{s}$, which is also the market price of the consumption good produced by sector $s$. Household $i$ 's consumer price index is given by

$$
P_{i, t}=\left[\left(1-\alpha^{i}\right)\left(P_{t}^{A}\right)^{1-\eta}+\alpha^{i}\left(P_{t}^{B}\right)^{1-\eta}\right]^{\frac{1}{1-\eta}} .
$$

Throughout, we assume that nominal bonds in the economy pay out in the price index $P_{t}^{A}$, so that the nominal bond position of a household of type $i$ is $P_{t}^{A} a_{i, t}$, where $a_{i, t}$ is the real bond position. We can derive the equation for the evolution of real wealth of a household of type $i$, which is

$$
\dot{a}_{i, t}=\left(i_{t}-\pi_{t}^{A}\right) a_{i, t}+\sum_{s} z_{i, t}^{s} n_{i, t}^{s} w_{i, t}^{s} \alpha_{t}^{\alpha^{i}}+\frac{T_{i, t}}{P_{t}^{A}}-p_{t}^{\alpha^{i}} c_{i, t}
$$

where $z_{i, t}^{s}$ is the stochastic labor productivity of household type $i$ in sector $s$, and $T_{i, t}$ is a lump-sum transfer. We define inflation in sector $A$ as $\pi_{t}^{A}=\frac{\dot{P}_{t}^{A}}{P_{t}^{A}}$, and household $i^{\prime}$ s real wage as $w_{i, t}^{s}=\frac{W_{i, t}^{s}}{P_{i, t}}$. Similarly, we define the economy's real interest rate as $r_{t}=i_{t}-\pi_{t}^{A}$. Finally, we define the relative producer prices in our economy as $p_{t}=\frac{P_{t}^{B}}{P_{t}^{A}}$, and set $\eta=1$ so that $P_{i, t}=\left(P_{t}^{A}\right)^{1-\alpha^{i}}\left(P_{t}^{B}\right)^{\alpha^{i}}$.

Household type $i$ 's borrowing constraint is given in real terms by

$$
a_{i, t} \geq \underline{a}
$$

where the household-specific borrowing limit is related to household $i$ 's natural borrowing limit under the stationary distribution.

We assume that the earnings process a household of type $i$ faces, $z_{i, t}^{s}$ follows an arbitrary diffusion process given by

$$
d z_{i, t}^{s}=\mu\left(z_{i, t}^{s}\right) d t+\sigma\left(z_{i, t}^{s}\right) d B_{t}
$$

This stochastic earnings process gives rise to within-type heterogeneity. That is, two households with College education will not be identical in our model because they face idiosyncratic earnings risk and, as a result, accumulate wealth as a precautionary buffer. Our model therefore features extensive within-education-type and across-education-type household heterogeneity.

We assume for now that the earnings processes are not sector-specific. Each household type has two household-level state variables, wealth $a_{i, t}$ and labor productivity $z_{i, t}$.

The household's problem can now be written recursively in terms of a Hamilton-Jacobi-Bellman (HJB) equation. The HJB equation implies a set of policy functions for consumption, $c_{i, t}\left(a_{i, t}, z_{i, t}^{s}\right)$, and labor, $n_{i, t}\left(a_{i, t}, z_{i, t}^{S}\right)$, which satisfy a labor-leisure condition given by

$$
c_{i, t}^{\gamma}\left(n_{i, t}^{s}\right)^{\phi}=z_{i, t}^{s} w_{i, t}^{s}
$$

for all $i$ and $s$. Moreover, we must have

$$
\frac{n_{i, t}^{A}}{n_{i, t}^{B}}=\left(\frac{w_{i, t}^{A}}{w_{i, t}^{B}}\right)^{\frac{1}{\phi}},
$$

since we assume that households' earnings processes are not sector specific. 


\subsection{Firms}

We next consider firms in our economy. We generalize the standard New Keynesian supply side by introducing heterogeneity across production sectors. In particular, our model features two production sectors, $s \in\{A, B\}$. These sectors have different degrees of price rigidity, which we define precisely below. Moreover, as we discussed above, the two production sectors differ in the education intensities of their production functions, so that in equilibrium sectors $A$ and $B$ will employ different shares of College and Non-College workers. Finally, firms in the two sectors face different demand from the two household types. Together, these extensions to a standard HANK model such as in Kaplan et al. (2017) allow us to study the two novel facts we present in this paper.

Sectoral production. In each sector $s \in\{A, B\}$ there is a retailer who purchases differentiated inputs from intermediate goods firms and bundles these into a sector-specific, final consumption good. This aggregation technology is CES and given by

$$
Y_{t}^{S}=\left(\int_{0}^{1} Y_{t}^{S}(j)^{\frac{\epsilon-1}{\epsilon}} d j\right)^{\frac{\epsilon}{\epsilon-1}},
$$

where $Y_{t}^{s}$ denotes total production in sector $s$.

Each retailer demands intermediate input $j$ according to the standard demand function

$$
Y_{t}^{s}(j)=\left(\frac{P_{t}^{S}(j)}{P_{t}^{s}}\right)^{-\epsilon} Y_{t}^{s} .
$$

Intermediate goods producers. The production technology of the producers of intermediate varieties in sector $s$ is given by

$$
Y_{t}^{s}(j)=A_{t} \sum_{i} Z_{i}^{s} N_{i, t}^{s}(j)
$$

Remark. Note that that the productivity coefficients $Z_{i}^{s}$ are distinct from $z_{i, t}^{s}$. The former is the constant labor skill intensity of sector $s$, while the latter is an idiosyncratically risky earnings process of household type $i$.

Firm $j$ is monopolistically competitive and sets the price on its differentiated variety, $P_{t}^{s}(j)$. Its total profits in period $t$ are given by

$$
\Pi_{t}^{s}(j)=P_{t}^{s}(j) Y_{t}^{s}(j)-\left(1-\tau^{L}\right) \sum_{i} W_{i, t}^{s} N_{i, t}^{s}(j),
$$

where $\tau^{L}$ is an employment subsidy and $W_{i, t}^{s}$ is the nominal wage rate paid by companies in sector $s$ to households of type $i$. That is, households of type $i$ compete in sector $s$ at the wage rate $W_{i, t}^{s}$. In equilibrium, therefore, we must have

$$
\frac{W_{C, t}^{s}}{Z_{C}^{s}}=\frac{W_{N C, t}^{s}}{Z_{N C}^{s}},
$$

in each sector $s$, as firms must be indifferent between the two employee types. 
The real marginal cost of firms in sector $s$, deflated by the producer price index of sector $s$, is thus given by

$$
M C_{t}^{s}=\frac{1-\tau^{L}}{A_{t}} \frac{W_{i, t}^{s}}{Z_{i}^{s} P_{t}^{s}}
$$

so that each firm $j$ in sector $s$ faces the same marginal cost.

Price-setting under flexible prices. If firm $j$ can set prices flexibly, it chooses $P_{t}^{s}(j)$ at all times $t$ to maximize $\Pi_{t}(j)$. The first-order condition with profit maximization then implies

$$
P_{t}^{s}(j)=\frac{\epsilon}{\epsilon-1} M C_{t}^{s} P_{t}^{s} .
$$

In the stationary equilibrium, we will have $P_{t}^{s}(j)=P_{t}^{s}$. The above condition then directly implies that the steady state real marginal cost is symmetric across sectors and given by the inverse of the markup, $M C_{t}^{s}=\frac{\epsilon-1}{\epsilon}$.

Note that in equilibrium firm symmetry implies that $Y_{t}^{s}(j)=Y_{t}^{s}, P_{t}^{s}(j)=P_{t}^{s}$, and

$$
\frac{\Pi_{t}^{s}}{P_{t}^{s}}=\frac{\Pi_{t}^{s}(j)}{P_{t}^{s}}=\left(1-M C_{t}^{s}\right) Y_{t}^{s} .
$$

Price-setting under sticky prices. We introduce price stickiness by assuming that each firm faces a Rotemberg (1982) adjustment cost when adjusting the price it charges on its goods. In particular, firm prices now follow the process

$$
d P_{t}^{s}(j)=\varphi_{t}^{s}(j) d t
$$

and the firm's decision criterion becomes

$$
\max _{\varphi_{t}^{s}(j)} \int_{0}^{\infty} e^{-\int_{0}^{t} i_{s} d s}\left[\Pi_{t}^{s}(j)-\Lambda\left(\varphi_{t}^{s}(j)\right)\right] d t,
$$

where $\Lambda\left(\varphi_{t}^{s}(j)\right)$ is the cost of adjusting prices at the rate $\varphi_{t}^{s}(j)$. Since aggregates in our model are deterministic, the firm's price optimization is a standard optimal control problem. We collect the solution to this problem in the following Lemma. For now, we assume an adjustment cost function given by

$$
\Lambda\left(\varphi_{t}^{s}\right)=\frac{\delta_{s}}{2}\left(\frac{\varphi_{t}^{s}}{P_{t}^{s}}\right)^{2} P_{t}^{s} Y_{t}^{s}
$$

and we define PPI inflation in sector $s$ as $\pi_{t}^{s}=\frac{\dot{P}_{t}^{s}}{P_{t}^{s}}$. To capture heterogeneous price stickiness across sectors, we allow for different sectoral price adjustment costs $\delta_{s}$.

Lemma 4. The New Keynesian Phillips Curves for each production sector of the economy can be written as

$$
\dot{\pi}_{t}^{s}=\pi_{t}^{s}\left(i_{t}-\pi_{t}^{s}-\frac{\dot{Y}_{t}^{s}}{Y_{t}^{s}}\right)-\frac{\epsilon-1}{\delta_{s}}\left(\frac{\epsilon}{\epsilon-1} M C_{t}^{s}-1\right) .
$$

Price dynamics in our model are therefore characterized by two Phillips Curves, one for each production sector. Since households' consumption baskets consist of different shares of the two sectors' goods, households will face different inflation processes as well. 


\subsection{Household transfers}

We can now characterize transfers to households, $T_{i, t}$. These transfers consist of two componenents, a lump-sum tax that the government uses as an employment subsidy and a rebate of firm profits.

Solving for transfers and firm profit rebates, we can rewrite household $i$ 's budget constraint as

$$
\dot{a}_{i, t}=r_{t} a_{i, t}+\sum_{s} z_{i, t}^{s} n_{i, t}^{s} w_{i, t}^{s} p_{t}^{\alpha^{i}}-p_{t}^{\alpha^{i}} c_{i, t}+\varphi_{i}\left[Y_{t}^{A}+p_{t} Y_{t}^{B}-\sum_{s} \sum_{i} w_{i, t}^{s} p_{t}^{\alpha^{i}} N_{i, t}^{s}\right],
$$

where $0 \leq \varphi_{i} \leq 1$ governs the share of firm profits received by household $i$.

It is well known that assumptions on the structure of these transfers have important consequences on the qualitative and quantitative features of heterogeneous agent models; see, for example, Farhi and Werning (2014) and Kaplan et al. (2017). Following the reasoning in Farhi and Werning (2014), we look for a set of assumptions on transfers that have the least consequential impact on our qualitative results. Since they study a hand-to-mouth model, their assumption of complete symmetry in transfers and rebates is the most conservative one. In our model, however, household types have different earnings levels even in steady state because we assume different educational backgrounds. Assuming symmetry in transfers and rebates would, therefore, benefit Non-College households disproportionately. In fact, the results from some of our quantitative exercises would be driven entirely by firm profit rebates under this assumption, because the cyclicality of firm profits is very large in New Keynesian models. In other words, under symmetric rebates the income effects we study below would be dwarved by the outsized transfer Non-College households receive from firms, relative to their steady state income, under the assumption that they own an even share of equity in our economy.

An alternative approach to this issue would entail calibrating the actual share of equity ownership across College and Non-College households in the economy. We are planning to pursue this direction as a robustness check in the future.

\subsection{Aggregation}

Let $g_{i, t}\left(x_{i, t}\right)$ denote the probability density of the diffusion process $d x_{i, t}=\left[d a_{i, t}, d z_{i, t}\right]$. It represents the density of household $i$ over the state space.

For aggregation, we can define aggregate consumption by household type $i$ as

$$
C_{i, t}=\int c_{i, t}\left(x_{i, t}\right) g_{i, t}\left(x_{i, t}\right) d x .
$$

The evolution of these density functions can then be written in terms of a Kolmogorov forward (KF) equation. We leave out the technical details about the KF equation from this section.

\subsection{Monetary policy}

The Fisher relation is given by

$$
r_{t}=i_{t}-\pi_{t}^{A}
$$

Monetary policy is given by the Taylor rule

$$
i_{t}=i_{t}^{*}+\sum_{s}\left(\phi_{\pi}^{s} \pi_{t}^{s}+\phi_{y}^{s}\left(Y_{t}^{s}-Y\right)\right)+\xi_{t}
$$


where $i_{t}^{*}$ is the world nominal interest rate and $\xi_{t}$ is a monetary policy innovation.

\section{Monetary policy transmission in the quantitative model}

In this section, we consider a one-time, unanticipated monetary policy shock $\xi_{0}$ at time 0 . In particular, we consider a 100bps shock with a half-life of about half a year. Our goal in this section is to characterize the implications of our novel facts for the real effects of monetary policy. Throughout, we will discuss both cross-sectional effects and aggregate effects.

Our quantitative model takes three important departures from a heterogeneous-agent New Keynesian model with a single asset, see Kaplan et al. (2017). First, our supply side consists of two production sectors with different degrees of price stickiness. Second, the two household types have different preferences for each of the two sectors' goods, thereby exposing them to the sectors' differential price stickiness. Finally, the two household types work in different sectors, giving rise to an earnings channel that interacts with heterogeneous price stickiness.

We summarize our benchmark calibration in Table 3 in the appendix. In Section 6.1, we start by discussing the implications of heterogeneous price stickiness for the effectiveness of monetary policy in a HANK model. To focus on heterogeneous price stickiness in isolation, we abstract from different household types in this subsection. We then introduce the second household type and study the earnings effects in Section 6.2 and the expenditures effects in Section 6.3.

\subsection{Heterogeneous price stickiness}

Heterogeneous price stickiness has been studied extensively in the context of the standard New Keynesian model. To the best of our knowledge, however, our model is the first to do so in the presence of rich household heterogeneity. We therefore think it is worthwhile to start by considering the implications of price stickiness heterogeneity across sectors in a HANK model without added household type heterogeneity, as in Kaplan et al. (2017).

For reference, we plot in Figure 9 the impulse response functions (IRFs) for a positive 100bps monetary policy shock in a HANK model without heterogeneity in production sectors. These IRFs correspond exactly to a single-asset version of Kaplan et al. (2017). In response to a monetary tightening, consumption, labor and output fall, and the economy experiences deflation.

In Figure 10, we present the IRFs for the same monetary policy shock in an economy featuring sectoral price stickiness heterogeneity. What stands out directly is that the two production sectors now respond quite differently in response to the shock, which can be seen in the second row of panels. By definition, prices fall by much less in the rigid-price sector A (the blue line). As a result, the output gap is significantly more persistent over time and returns to steady state only after about 10 years. In the absence of heterogeneity in price stickiness, the output gap in both sectors closed much faster, with output returning to steady state after about 2.5 years.

Overall, the economy featuring sectoral heterogeneity exhibits considerably more persistence after the monetary policy shock. This finding is consistent with earlier work in the context of the standard NK model. Consumption and labor supply normalize considerably more slowly as well. 
While the output gap in the rigid-price sector remains large for some time, both output and inflation actually overshoot in the flexible-price sector. In that sense, Sector B can capture some of the shortfall of Sector A. In fact, the output gap in Sector B becomes positive much more quickly than the output gap normalized to 0 in the benchmark HANK model. The relatively good performance of the flexible-price sector is in part driven by a fall in the relative price of its goods, which can be seen in the bottom left panel.

The most marked difference between the two models, however, is that the real effect of monetary policy is significantly muted, on impact, when we account for sectoral heterogeneity. This finding is in contrast to some earlier work. In fact, the output gap response on impact is only about a third as large as that in the benchmark HANK model. The same holds for consumption and labor supply. When we account for sectoral heterogeneity, we effectively allow consumers to shift away from the goods of the rigid-price sector and instead purchase from the flexible-price sector whose price fell and became more competitive. In a sense, this insulates household demand from the friction of price stickiness.

\subsection{The earnings channel of monetary policy}

Having considered the implications of sectoral heterogeneity in isolation, we now add household heterogeneity. We do so in two steps. First, in this subsection, we consider a model with two household types, and of course within-type heterogeneity, featuring symmetric productivity differences. That is, we assume College households are simply more productive than Non-College households, but not particularly more so in one relative to the other sector.

The results of this exercise are presented in Figure 11. The first marked observation is that the equilibrium real interest rate is over 100bps lower in this model than in the benchmark HANK model. While we have confirmed that this does not affect our results in terms of deviations from steady state values, it is a finding worthy of some discussion. Households in our model anticipate that they may switch education types in the future. For College households, this represents a significant negative earnings risk, incentivizing them to save more. In other words, richer and more educated households today understand that their children may not become as educated and therefore have lower earnings potential. To provide insurance against this, more educated households save more today. Similarly, Non-College households anticipate a positive earnings shock in the future, in the form of switching to the College type. As a result, these households have an additional incentive to dissave today. Together, these two forces suppress the real interest rate that obtains in stationary equilibrium.

Overall, the differences, in terms of deviations from steady state, between this simple model of household heterogeneity and the HANK model with only sectoral heterogeneity are not large. In fact, the quantitative differences in inflation and output responses across sectors are hardly noticable. College households experience a slightly larger fall in their consumption on impact but then revert back to their steady state consumption level faster.

\subsection{Interaction of our two novel channels}

When we allow for both dimensions of household heterogeneity to interact, quantitatively large differences from the HANK model with only sectoral heterogeneity emerge. 
Most noticably, the two household types are affected very differently by monetary policy. College households are significantly more sensitive to monetary policy; their consumption falls by $30 \%$ more than that of Non-College households in response to a monetary tightening. College households also do not let their labor supply fall by nearly as much as Non-College households. It is important to note that $22 \%$ of this discrepancy are driven entirely by the two channels we document in this paper, rather than any of the other sources of heterogeneity featured in our model. In other words, what is driving these cross-sectional effects of monetary policy is not that College households are more productive on average, but that they are more productive in and consume more from the rigid-price sector. This can be seen by comparing Figure 11 to Figure 12.

In aggregate terms, this adds up to a 5\% larger output gap, on impact, in the rigid-price sector which College households have more exposure to.

\subsection{Counter-factual exercises}

In ongoing work, we document the importance of heterogeneous price rigidities when considering the implication of several trends in the U.S. economy.

First, we study the implications of structural change for monetary policy in the presence of heterogeneous rigidities. Structural change refers to the rising share of services into total consumption expenditures and total payroll. Intuitively, as services become relatively more important, the economy becomes more exposed to price rigidities due to both earnings and expenditure channels. Using the model, we can quantify the extent to which structural change makes monetary policy more potent by increasing the effective degree of price rigidities in the economy.

In addition, the rise in inequality over the last four decades may also have important implications for monetary policy in our setting. Richer and more educated households are significantly more sensitive to monetary policy when accounting for the earnings and expenditure channels. As a result, monetary policy should become more powerful in real terms as inequality increases.

\section{Conclusion}

In this paper, we have investigated the implications of heterogeneous price rigidities across sectors for the distributional and aggregate effects of monetary policy. Compared to a counterfactual economy with homogeneous price rigidities, we found that in the presence of heterogeneous rigidities the consumption of college-educated household is 22 percent more sensitive to monetary policy shocks as that of non-college households, and the aggregate real effect of monetary policy is 5 percent stronger. This finding stems from the fact that prices are less rigid in sectors employing college-educated households (earnings channel) as well as in sectors selling more to college-educated households (expenditures channel). Accounting for both of these channels and their interaction, our HANK model shows that heterogeneous rigidities slightly strengthen the aggregate real effect of monetary policy and create a substantial distributional effect in favor of college-educated households. 
Table 1: Summary Statistics for Linked Datasets

Panel A: CPI-ACS Sample (2000-2015)

\begin{tabular}{lccccc}
\hline Variable & Mean & St. Dev. & Median & p5 & p95 \\
\hline \hline Frequency of Price Changes, All & 16.51 & 14.07 & 10.08 & 3.37 & 37.95 \\
Frequency of Price Changes, No Sales & 11.29 & 12.47 & 5.90 & 3.37 & 37.85 \\
Share of Payroll to College Graduates & 66.63 & 19.37 & 70.86 & 31.69 & 89.05 \\
Share of Payroll to Workers Earning > \$60k & 43.30 & 16.82 & 42.41 & 17.51 & 73.55 \\
& & & & & \\
Number of Industries & 94 & & & & \\
\hline
\end{tabular}

Panel B: PPI-ACS Sample (2000-2015)

\begin{tabular}{lccccc}
\hline Variable & Mean & St. Dev. & Median & p5 & p95 \\
\hline \hline Frequency of Price Changes, All & 17.64 & 15.70 & 12.12 & 5.13 & 60.18 \\
Share of Payroll to College Graduates & 67.03 & 19.69 & 71.77 & 37.72 & 92.20 \\
Share of Payroll to Workers Earning $>\$ 60 \mathrm{k}$ & 49.45 & 16.97 & 50.51 & 21.60 & 77.27 \\
& & & & & \\
Number of Industries & 169 & & & & \\
\hline
\end{tabular}

Panel C: CPI-CEX Sample (2004-2015)

\begin{tabular}{lccccc}
\hline Variable & Mean & St. Dev. & Median & p5 & p95 \\
\hline \hline Frequency of Price Changes, All & 26.19 & 24.78 & 18.94 & 3.31 & 87.60 \\
Frequency of Price Changes, No Sales & 20.60 & 25.59 & 8.46 & 2.85 & 85.57 \\
Share of Sales to College Graduates & 41.01 & 11.02 & 38.89 & 21.98 & 60.90 \\
Share of Sales to Households Earning $>$ \$60k & 59.01 & 10.04 & 56.61 & 45.46 & 75.57 \\
& & & & & \\
Sample Size & 254 & & & & \\
\hline
\end{tabular}

Notes: This table uses the three linked datasets described in Section 3.1. Panels A and B report summary statistics using payroll weights, while Panel C uses spending weights. 
Table 2: Relationships between Price Rigidities and Shares of College Graduates in Payroll or Sales

Panel A: Share of Payroll to College Graduates, CPI-ACS Sample

\begin{tabular}{lcccccc}
\hline & \multicolumn{5}{c}{ Share of Payroll to College Graduates (\%) } \\
\cline { 2 - 7 } & $(1)$ & $(2)$ & $(3)$ & $(4)$ & $(5)$ & $(6)$ \\
\hline \hline Frequency of Price Changes (\%), All & $-0.9330^{* * *}$ & $-0.463^{* *}$ & $-0.5505^{* *}$ & & & \\
Frequency of Price Changes (\%), No Sales & $(0.2649)$ & $(0.2119)$ & $(0.2396)$ & & & \\
& & & & $-0.6116^{* *}$ & -0.1780 & -0.2106 \\
Excluding industries with & & & & & & \\
price change frequency > p95 & Yes & Yes & No & Yes & Yes & No \\
2-digit Naics Code Fixed Effects & No & Yes & No & No & Yes & No \\
Sample Size & 86 & 86 & 94 & 87 & 87 & 94 \\
\hline
\end{tabular}

Panel B: Share of Payroll to College Graduates, PPI-ACS Sample

\begin{tabular}{lccc}
\hline & \multicolumn{3}{c}{ Share of Payroll to College Graduates (\%) } \\
\cline { 2 - 4 } & $(1)$ & $(2)$ & $(3)$ \\
\hline \hline Frequency of Price Changes (\%), All & $-0.9823^{* * *}$ & -0.2027 & $-0.3771^{*}$ \\
& $(0.2149)$ & $(0.1306)$ & $(0.1978)$ \\
$\begin{array}{l}\text { Excluding industries with } \\
\text { price change frequency > p95 }\end{array}$ & Yes & Yes & No \\
2-digit Naics Code Fixed Effects & No & Yes & No \\
Sample Size & 163 & 163 & 169 \\
\hline
\end{tabular}

Panel C: Share of Sales to College Graduates, CPI-CEX Sample

\begin{tabular}{lcccccc}
\hline & \multicolumn{5}{c}{ Share of Sales to College Graduates (\%) } \\
\cline { 2 - 7 } & $(1)$ & $(2)$ & $(3)$ & $(4)$ & $(5)$ & $(6)$ \\
\hline \hline Frequency of Price Changes (\%), All & $-0.2108^{* *}$ & $-0.1904^{*}$ & $-0.1256^{* *}$ & & & \\
& $(0.0824)$ & $(0.0977)$ & $(0.0376)$ & & & \\
Frequency of Price Changes (\%), No Sales & & & & -0.1492 & -0.0989 & $-0.0890^{* *}$ \\
& & & & $(0.1264)$ & $(0.1336)$ & $(0.0382)$ \\
Excluding industries with & & & & & & \\
price change frequency > p95 & Yes & Yes & No & Yes & Yes & No \\
Expenditure Category Fixed Effects & No & Yes & No & No & Yes & No \\
Sample Size & 242 & 242 & 254 & 246 & 246 & 254 \\
\hline
\end{tabular}

Notes: The specifications reported in this Table are discussed in Section 4.1. The specifications in Panels A and B all use total payroll weights, while spending weights are used for those reported in Panel C. Heteroskedastictiy-robust standard errors are reported. ${ }^{*} p<0.1,{ }^{* *} p<0.05,{ }^{* * *} p<0.01$. 
Table 3: Calibration Parameters

\begin{tabular}{|c|c|c|c|}
\hline & & Value & Source \\
\hline$\phi$ & $\begin{array}{l}\text { Curvature of (relative) } \\
\text { labor supply curve }\end{array}$ & 1.5 & Smets and Wouters (2007) \\
\hline $\begin{array}{c}\theta_{C} \\
\theta_{N C}\end{array}$ & $\begin{array}{l}\text { P(Non-College I College }) \\
\text { P(College I Non-College })\end{array}$ & $\begin{array}{l}0.45 / 35 \\
0.22 / 35\end{array}$ & Ferrare (2016) \\
\hline$\epsilon$ & $\begin{array}{l}\text { Elasticity of substitution } \\
\text { between intermediates }\end{array}$ & 11 & Basu and Fernald (1997) \\
\hline$\gamma$ & $\begin{array}{l}\text { CRRA for upper-level } \\
\text { utility function }\end{array}$ & 1.5 & $\mathrm{~N} / \mathrm{A}$ \\
\hline $\begin{array}{l}1-\alpha^{N C} \\
1-\alpha^{C}\end{array}$ & $\begin{array}{l}\text { Non-college spending in A } \\
\text { College spending in A }\end{array}$ & $\begin{array}{l}41.5 \% \\
58.5 \%\end{array}$ & CEX \\
\hline $\begin{array}{l}Z_{A}^{N C} \\
Z_{A}^{C} \\
Z_{B}^{N C} \\
Z_{B}^{C}\end{array}$ & $\begin{array}{c}\text { Non-college prod in A } \\
\text { College prod in A, normalized } \\
\text { Non-college prod in B } \\
\text { College prod in B }\end{array}$ & $\begin{array}{l}0.33 \\
1.14 \\
0.47 \\
0.66\end{array}$ & ACS \\
\hline $\begin{array}{l}\delta^{A} \\
\delta^{B}\end{array}$ & $\begin{array}{l}\text { Price adj. cost in A } \\
\text { Price adj. cost in B }\end{array}$ & $\begin{array}{c}190 \\
10\end{array}$ & Nakamura and Steinsson (2008) \\
\hline
\end{tabular}

Notes: This table reports the parameter values for the calibration discussed in Section 6. 
Figure 1: Earnings Channel by Education Groups

Panel A: Price Rigidities and College Payroll Shares, CPI-ACS Sample

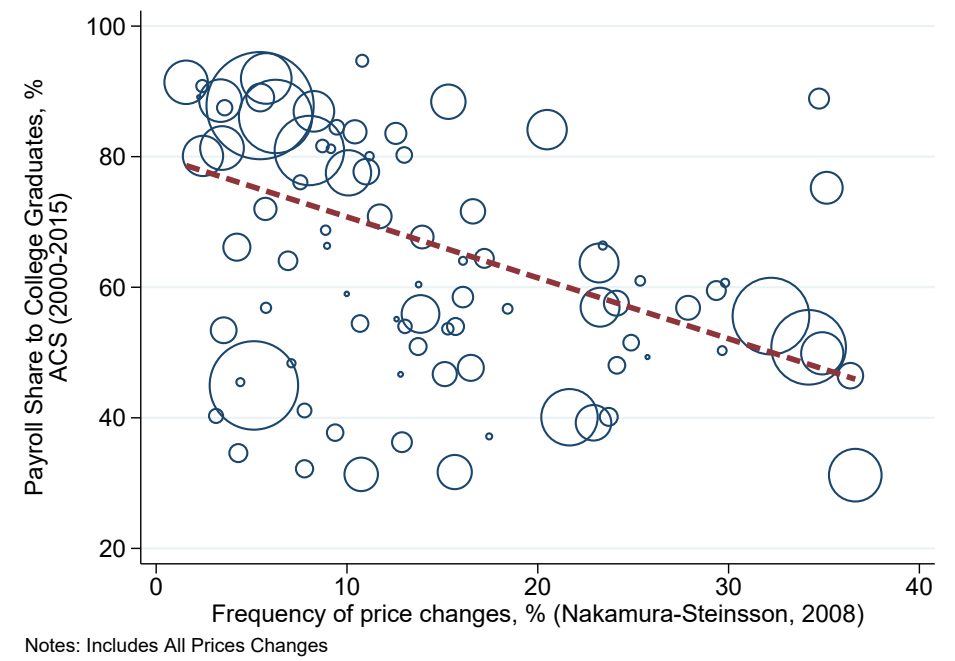

Panel B: Price Rigidities and College Payroll Shares, PPI-ACS Sample

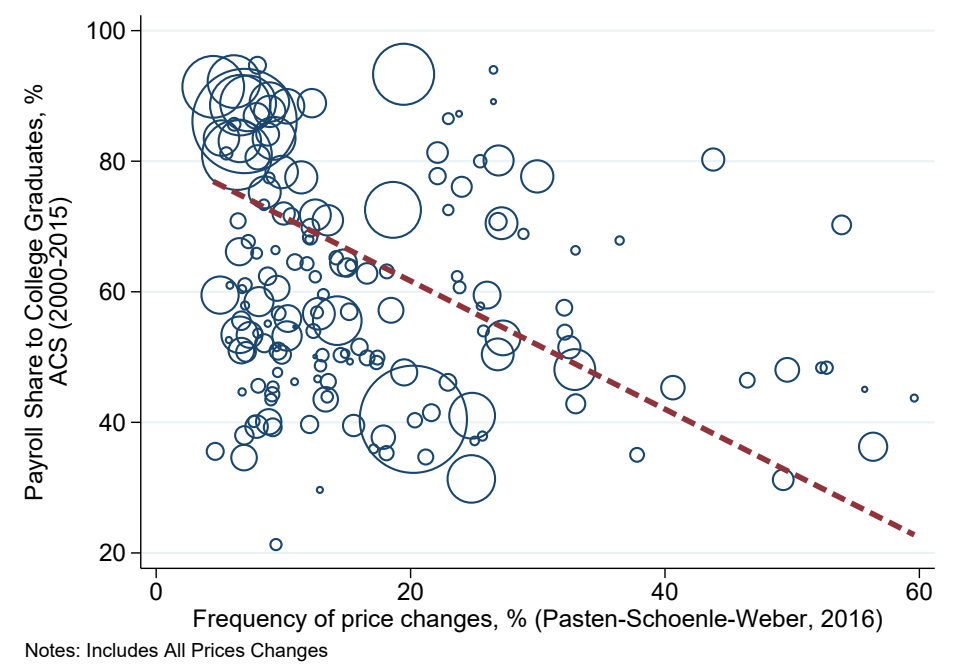

Notes: In both panels, each circle represents one ACS industry. Total payroll is used as regression weight and the size of each circle reflects the weight of each industry. The dashed red line is the OLS best-fit line. Panel A uses the CPIACS sample (only final consumption industries) while Panel B uses the PPI-ACS sample (accounting for intermediates industries); both datasets are described in Section 3.1. 
Figure 2: Expenditure Channel by Education Groups (Price Rigidities and College Spending Shares, CPICEX Sample)

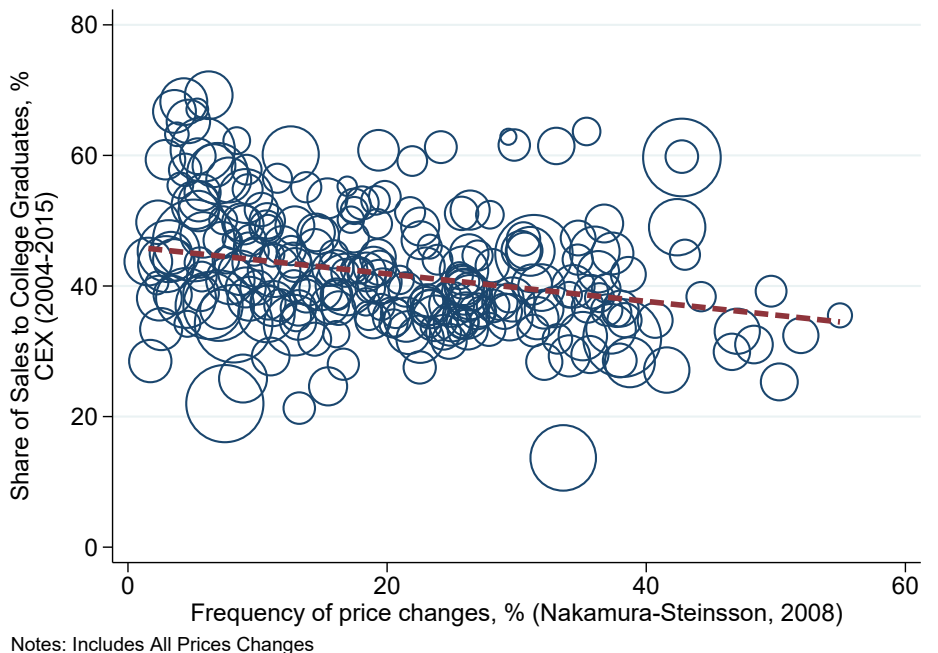

Notes: Each circle in this figure represents one ELI product category from the CPI-CEX sample, described in Section 3.1. Total spending is used as regression weight and the size of each circle indicates the weight of each product category. The dashed red line is the OLS best-fit line.

Figure 3: Interaction between Earnings and Expenditure Channels

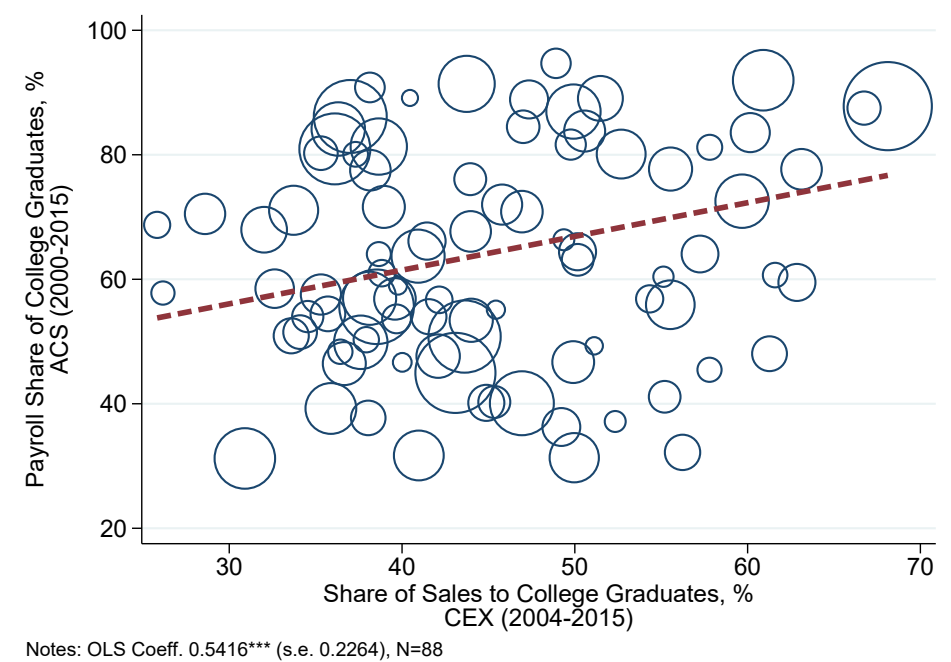

Notes: Each circle in this figure represents one ACS industry. The underlying data is described in Section 3.1. Total payroll is used as regression weight and the size of each circle indicates the weight of industry. The dashed red line is the OLS best-fit line. 
Figure 4: Robustness to Sample and Variable Definitions

Panel A: Price Rigidities and Income Elasticities

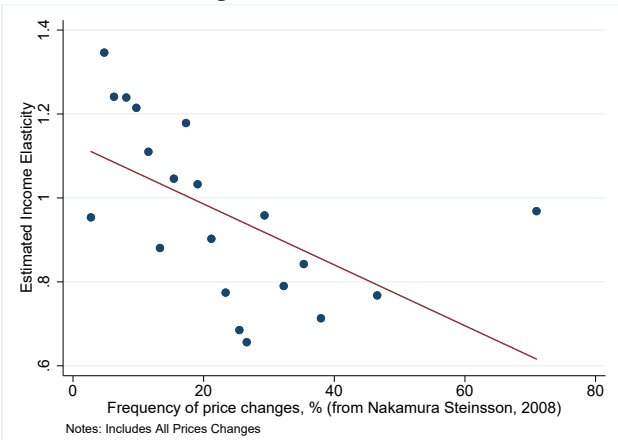

Panel B: Income Elasticities and College Payroll Shares

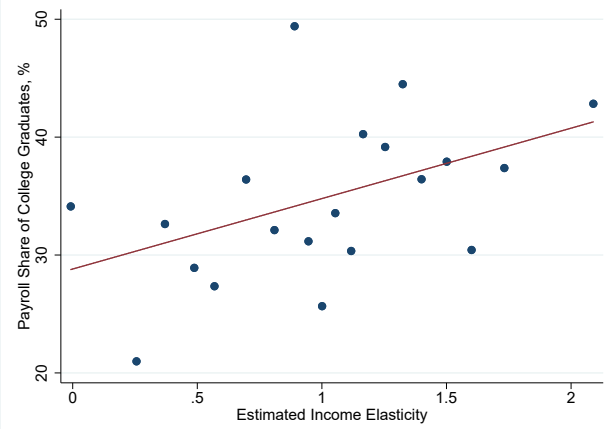

Panel C: Price Rigidities and Share of Sales to HH Earning $>\$ 60 \mathrm{k}$

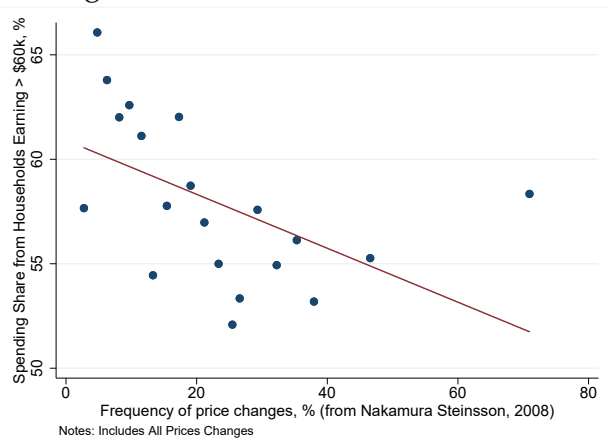

Notes: In these figures, each dot represents $5 \%$ of the underlying data. These specifications are discussed in Section 4.1 and the data is presented in Section 3.1. 
Figure 5: Robustness across Samples Periods

Panel A: Rigidities and College Payroll Share in CPI-ACS Sample

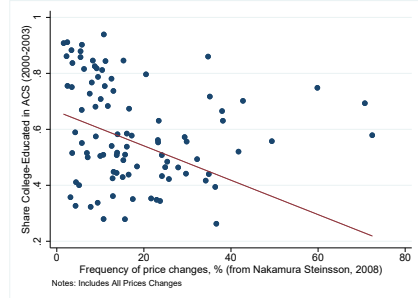

2000-2003

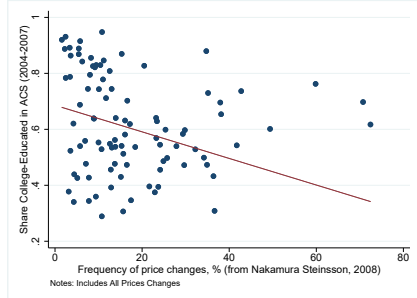

2004-2007

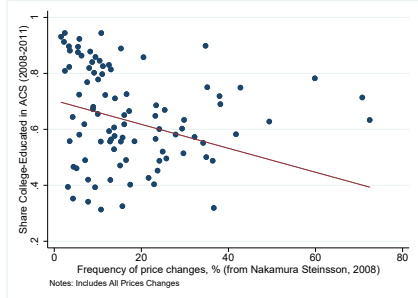

2008-2011

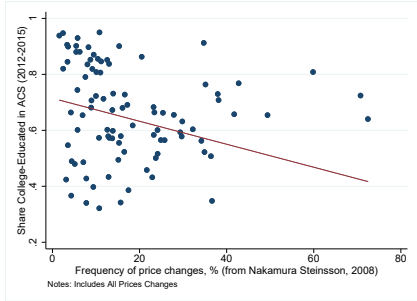

2012-2015

Panel B: Rigidities and College Payroll Share in PPI-ACS Sample

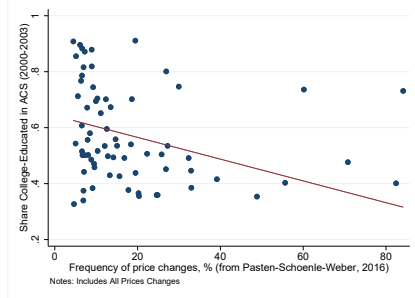

2000-2003

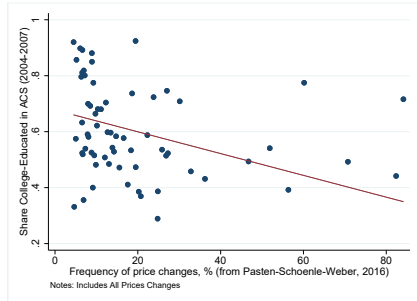

2004-2007

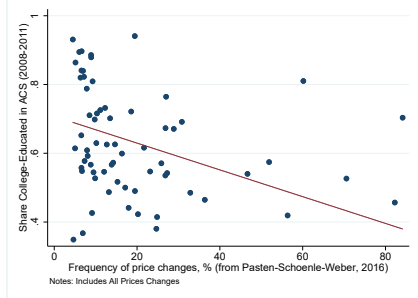

2008-2011

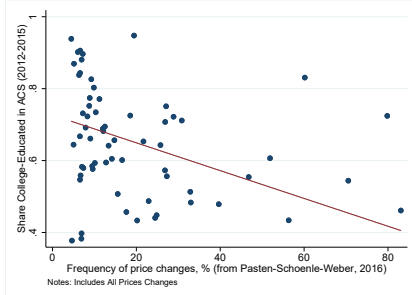

2012-2015

Panel C: Rigidities and Share of Sales fo College Graduates in CPI-CEX Sample

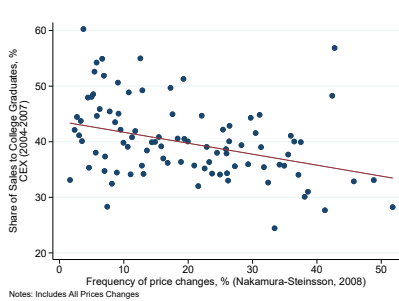

2004-2007

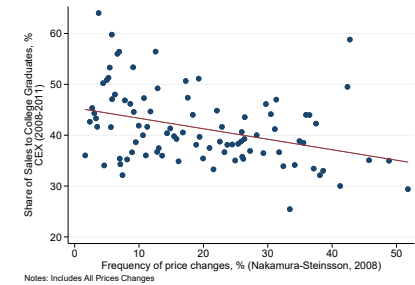

2008-2011

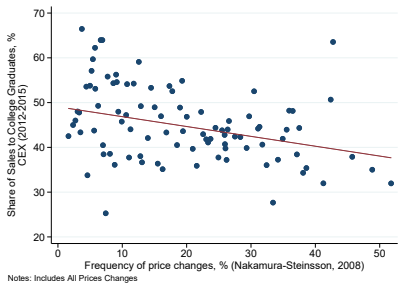

2012-2015

Notes: In these figures, each dot represents $5 \%$ of the underlying data. These specifications and samples are discussed in Section 4.1 and the data is presented in Section 3.1. 
Figure 6: Average Price Rigidity for Goods vs. Services

Panel A: With Expenditure Weights

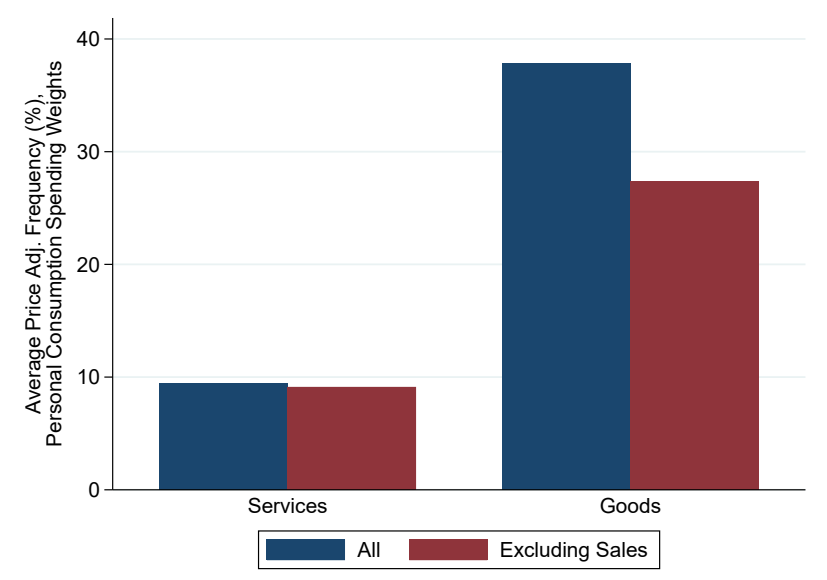

Panel B: With Payroll Weights

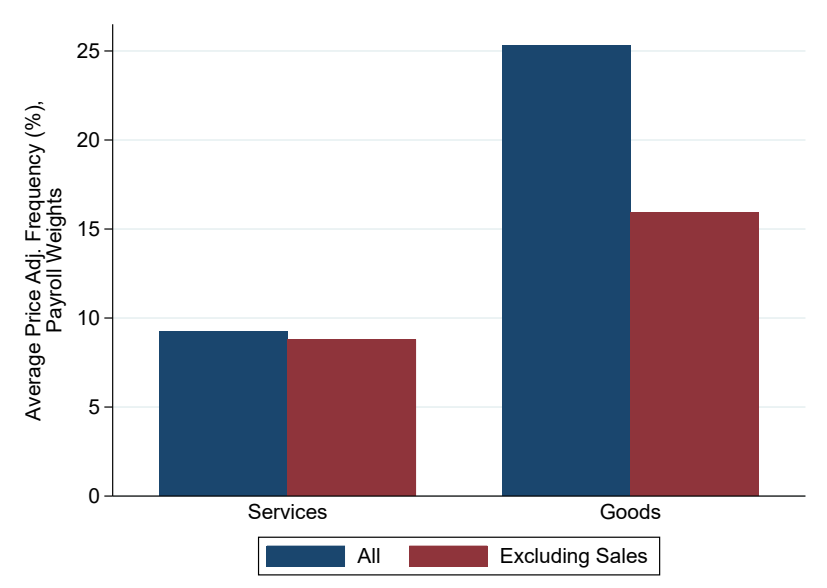

Panel C: With Output Weights

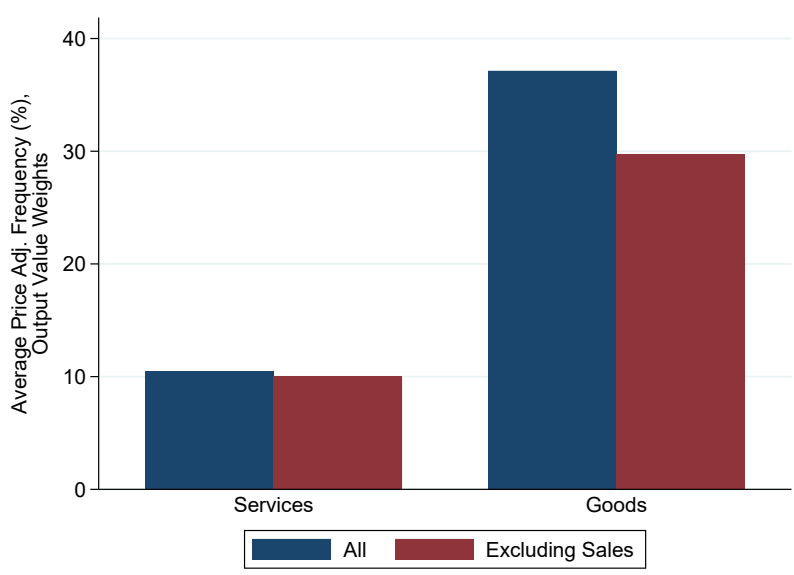

Notes: The various panels of the figure report heterogeneity in price rigidities across goods and services. The data is described in Section 3.1 and the patterns are discussed in Section 4.2. 
Figure 7: Average Price Rigidities Across Sectors

Panel A: With Expenditure Weights

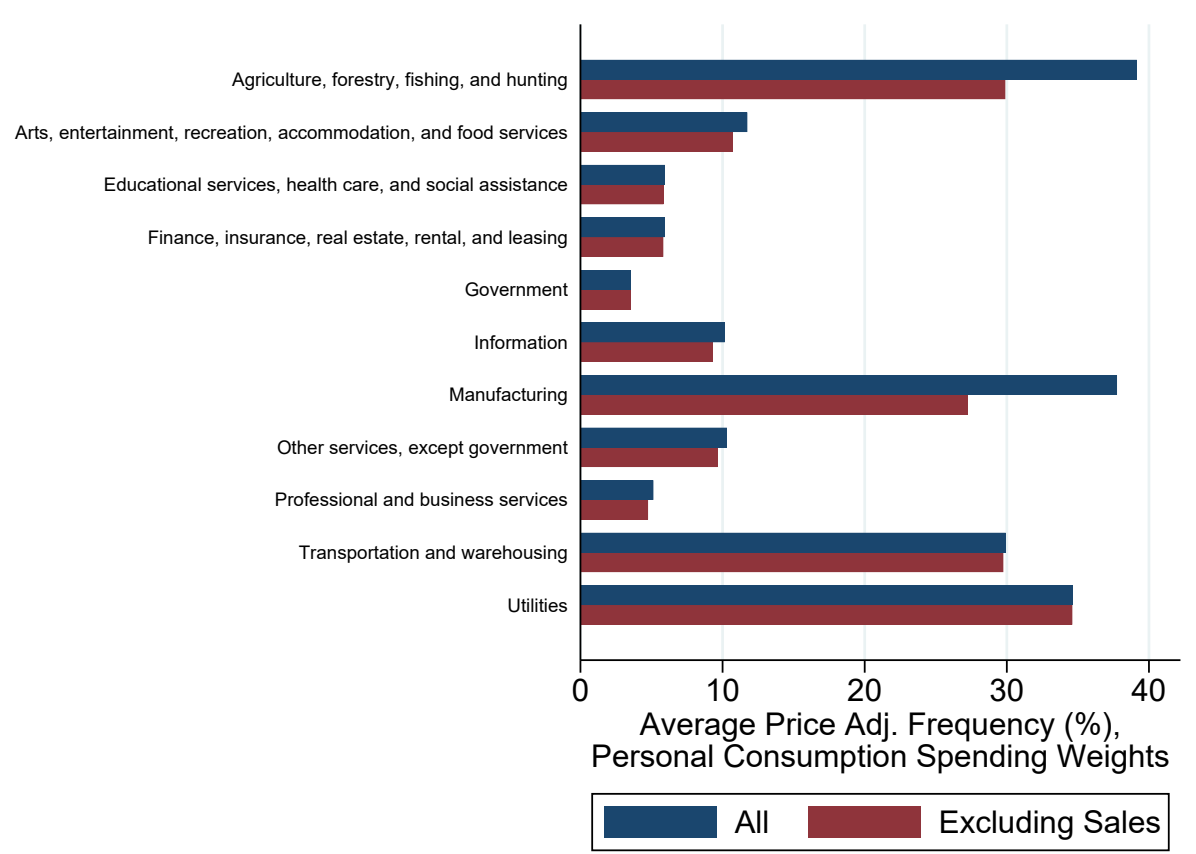

Panel B: With Payroll Weights

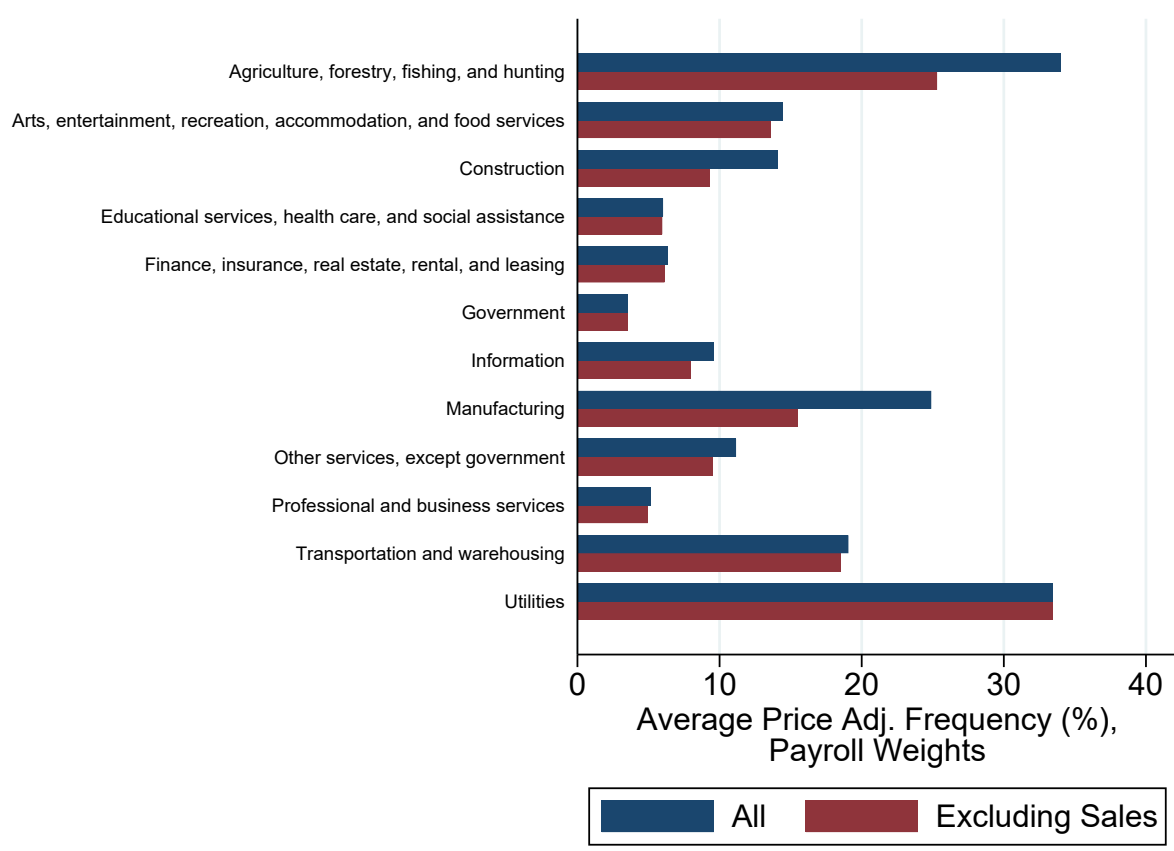

Notes: This figure documents heterogeneity in price rigidities across subsectors. The data is described in Section 3.1 and the patterns are discussed in Section 4.2. 
Figure 8: Structural Change and Price Rigidities

Panel A: The Secular Fall in the Spending Share on Goods (from Boppart, 2014)

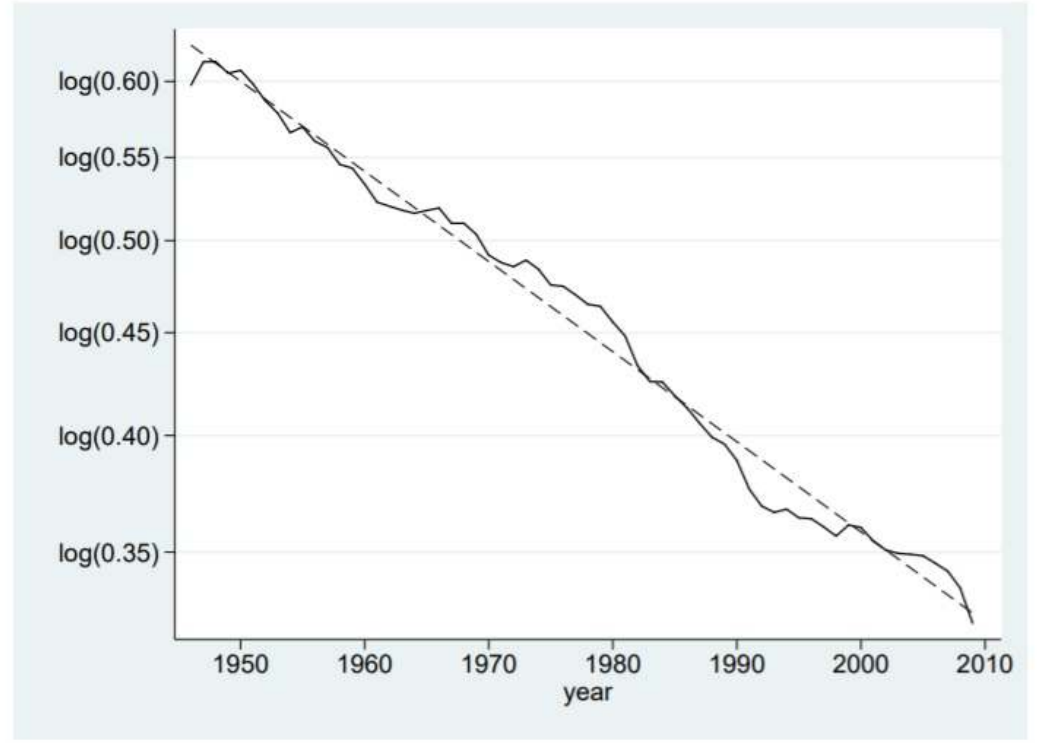

Figure 1: Logarithm of expenditure share of goods.

Notes: The figure plots the logarithm of the share of personal consumption expenditures devoted to goods in the U.S. The dashed attains an $R^{2}$ of 0.986 . In levels the expenditure share of goods declined from 0.60 in 1946 to 0.32 in 2009 . Source: BEA, NIPA table attains

Panel B: Implied Fall in Average Price Rigidity (Expenditure Weighted)

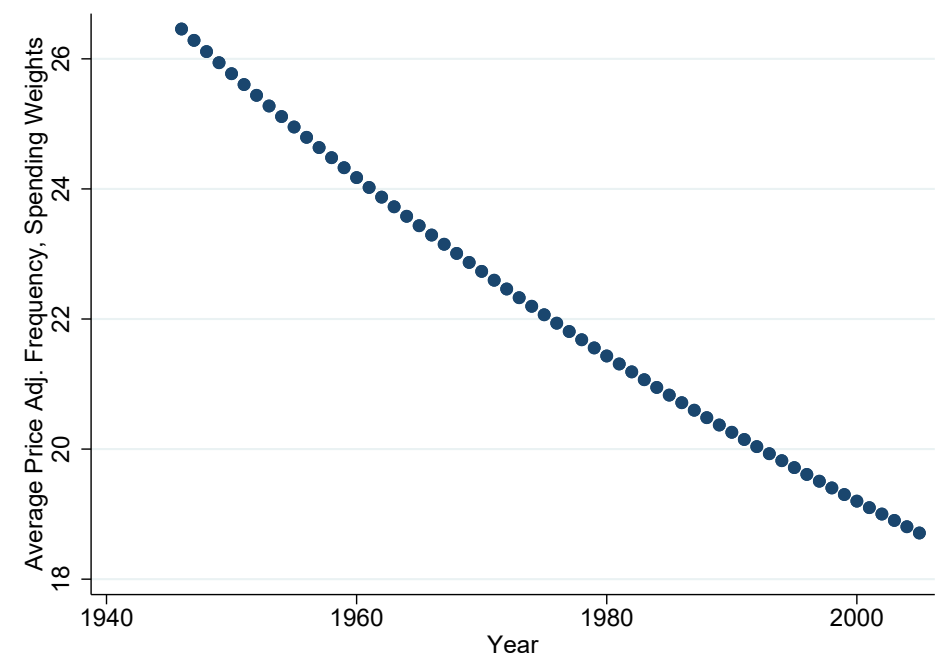

Notes: This figure documents the implication of the decline in the expenditure share of goods for average price rigidities in the U.S. economy. The data is described in Section 3.1 and the results are discussed in Section 4.2. 
Figure 9: Baseline HANK model
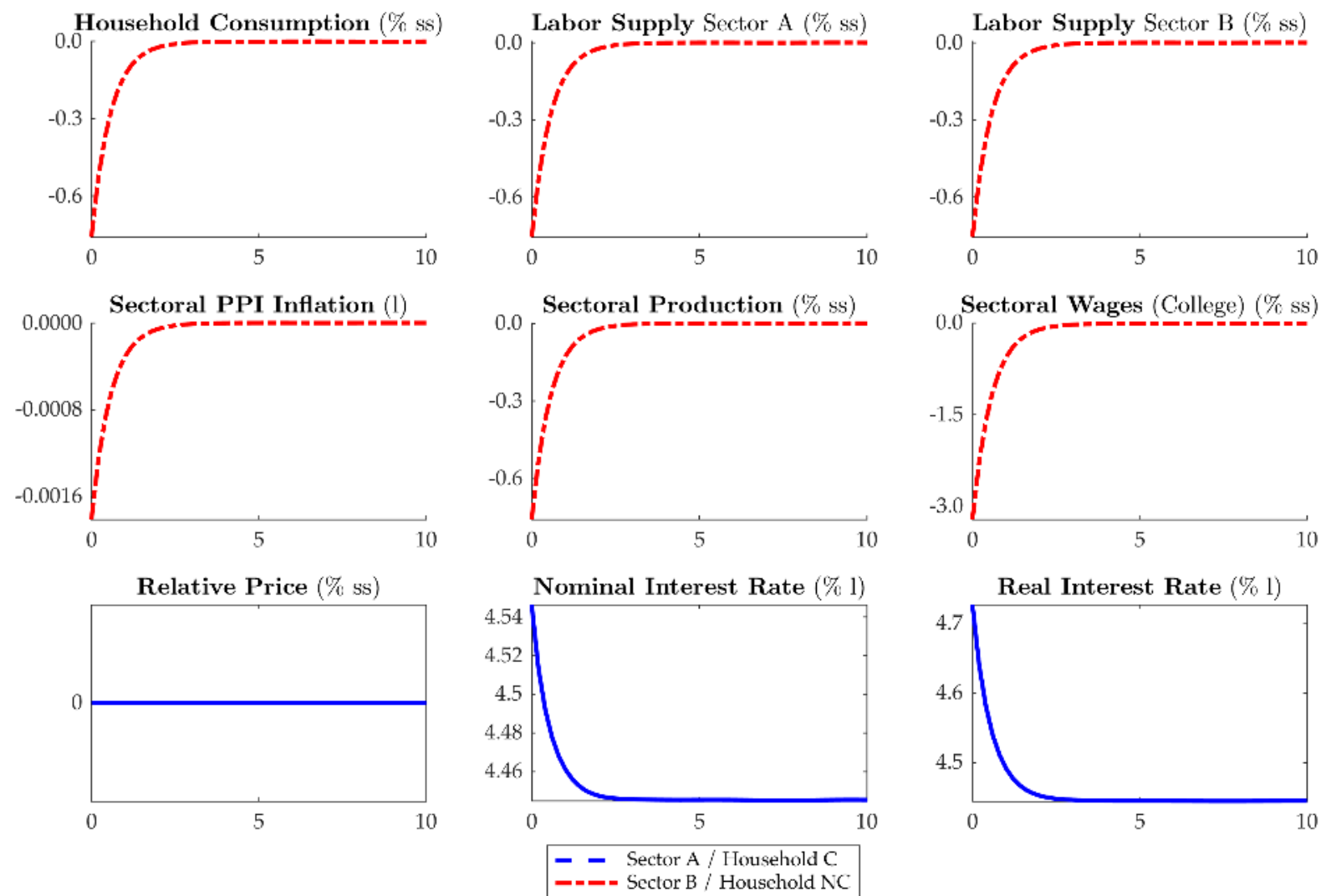

Notes: This Figure plots the impulse response functions of our baseline HANK economy after a 100bps monetary policy shock $\xi_{0}$. Our baseline HANK model is identical to a single-asset version of the model presented in Kaplan et al. (2017).

Throughout, we refer to the rigid-price sector as Sector A and the flexible-price sector as Sector B. The first two rows of panels feature two lines: In the first row, the blue line refers to College households and the red line to Non-College households; in the second row, the blue line refers to Sector A and the red line to Sector B. The first row of panels plots quantities related to household decisions: consumption, labor supply in Sector A and labor supply in Sector B. Whenever the red and blue lines coincide (so that only the red line is visible as it is here), then College and Non-College households behave identically. The second row of panels plots quantities and prices related to sectoral production: PPI inflation, output and wages. Whenever the red and blue lines coincide (so that only the red line is visible as it is here), then firms in Sector A and Sector B behave identically. The last row plots the relative price between goods produced in Sectors B and A, the nominal and the real interest rate. We do not plot the exogenous monetary policy shock. 
Figure 10: Heterogeneous production sectors
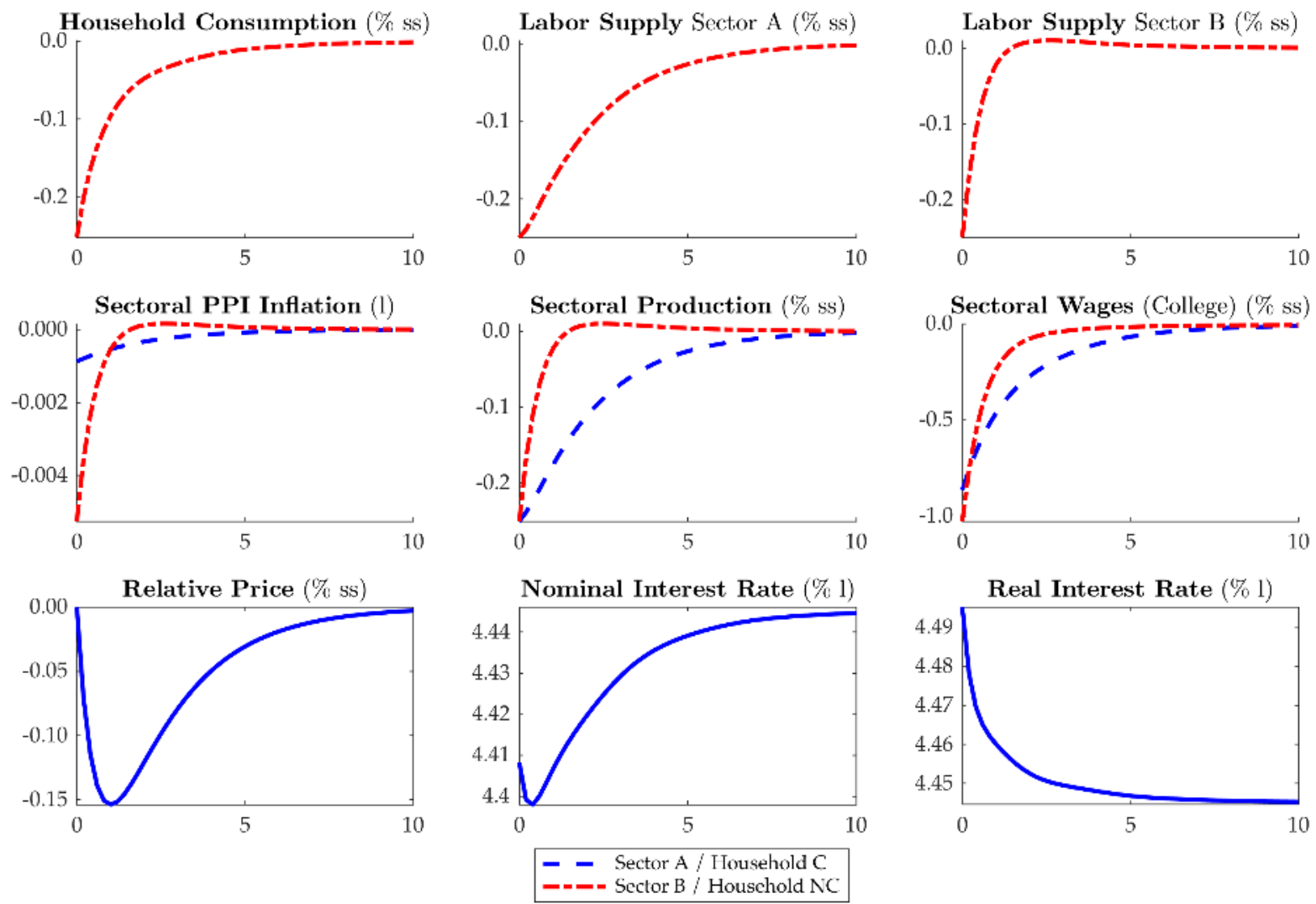

Notes: This Figure plots the impulse response functions after a $100 \mathrm{bps}$ monetary policy shock $\xi_{0}$. The economy under consideration is our baseline HANK model featuring one extension: we introduce a second production sector and allow for heterogeneous price rigidity across these sectors. Households are still identical.

Throughout, we refer to the rigid-price sector as Sector A and the flexible-price sector as Sector B. The first two rows of panels feature two lines: In the first row, the blue line refers to College households and the red line to Non-College households; in the second row, the blue line refers to Sector A and the red line to Sector B. The first row of panels plots quantities related to household decisions: consumption, labor supply in Sector A and labor supply in Sector B. Whenever the red and blue lines coincide (so that only the red line is visible as it is here), then College and Non-College households behave identically. The second row of panels plots quantities and prices related to sectoral production: PPI inflation, output and wages. The last row plots the relative price between goods produced in Sectors B and A, the nominal and the real interest rate. We do not plot the exogenous monetary policy shock. 
Figure 11: Adding symmetric productivity differences
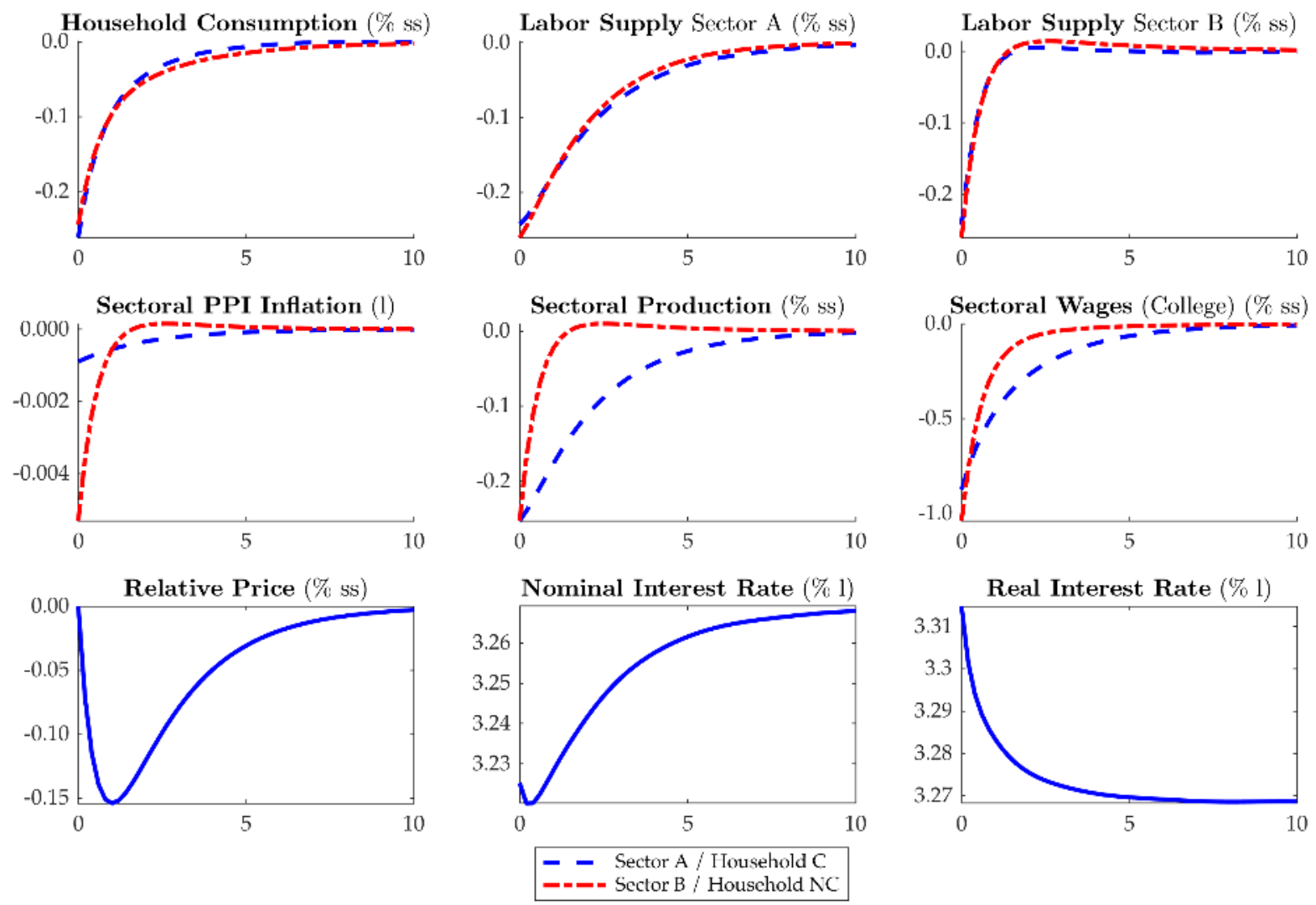

Notes: This Figure plots the impulse response functions after a $100 \mathrm{bps}$ monetary policy shock $\xi_{0}$. The economy under consideration is our baseline HANK model featuring two extensions. As before, we allow for heterogeneous price rigidity. Furthermore, we now introduce the second household type, so that households differ by education. For now, we capture educational heterogeneity as a constant and symmetric labor productivity gap.

Throughout, we refer to the rigid-price sector as Sector A and the flexible-price sector as Sector B. The first two rows of panels feature two lines: In the first row, the blue line refers to College households and the red line to Non-College households; in the second row, the blue line refers to Sector A and the red line to Sector B. The first row of panels plots quantities related to household decisions: consumption, labor supply in Sector A and labor supply in Sector B. The second row of panels plots quantities and prices related to sectoral production: PPI inflation, output and wages. The last row plots the relative price between goods produced in Sectors B and A, the nominal and the real interest rate. We do not plot the exogenous monetary policy shock. 
Figure 12: Our full quantitative model
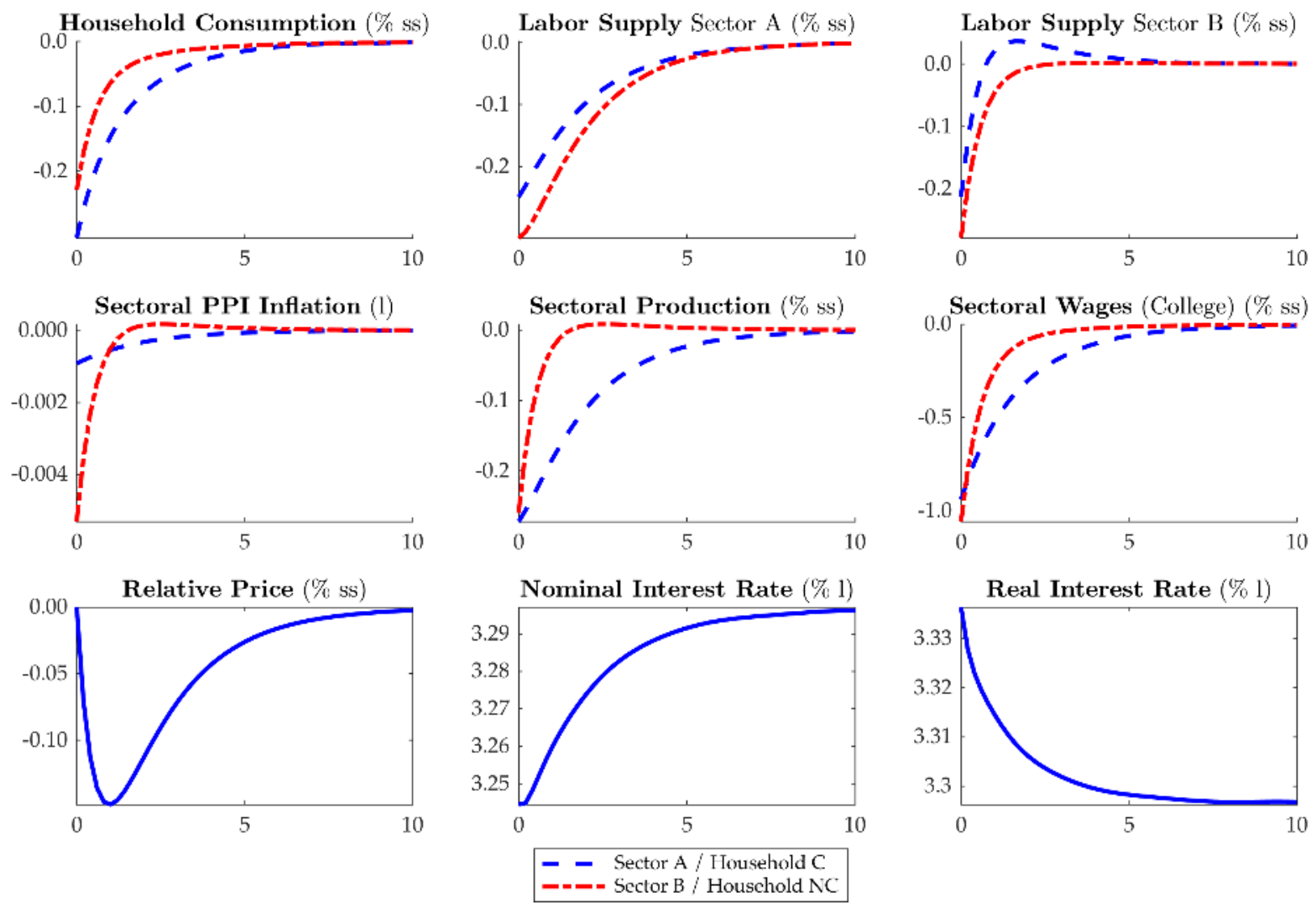

Notes: This Figure plots the impulse response functions after a $100 \mathrm{bps}$ monetary policy shock $\xi_{0}$. The economy under consideration is the quantitative model presented in the previous section, featuring both firm and household type heterogeneity.

Throughout, we refer to the rigid-price sector as Sector A and the flexible-price sector as Sector B. The first two rows of panels feature two lines: In the first row, the blue line refers to College households and the red line to Non-College households; in the second row, the blue line refers to Sector A and the red line to Sector B. The first row of panels plots quantities related to household decisions: consumption, labor supply in Sector A and labor supply in Sector B. The second row of panels plots quantities and prices related to sectoral production: PPI inflation, output and wages. The last row plots the relative price between goods produced in Sectors B and A, the nominal and the real interest rate. We do not plot the exogenous monetary policy shock. 


\section{References}

Albanesi, S. (2007). Inflation and inequality. Journal of Monetary Economics 54(4), 1088-1114.

Auclert, A. (2017). Monetary policy and the redistribution channel. Technical report, National Bureau of Economic Research.

Boppart, T. (2014). Structural change and the Kaldor facts in a growth model with relative price effects and non-Gorman preferences. Econometrica 82(6), 2167-2196.

Borusyak, K. and X. Jaravel (2017). The Distributional Effects of Trade: Theory and Evidence from the United States. Technical report, Working Paper.

Carpenter, S. B. and W. M. Rodgers III (2004). The disparate labor market impacts of monetary policy. Journal of Policy Analysis and Management 23(4), 813-830.

Coibion, O., Y. Gorodnichenko, L. Kueng, and J. Silvia (2017). Innocent Bystanders? Monetary policy and inequality. Journal of Monetary Economics 88, 70-89.

Comin, D., D. Lashkari, and M. Mestieri (2018). DP10846 Structural Change with Long-run Income and Price Effects.

Cravino, J., T. Lan, and A. A. Levchenko (2018). Price Stickiness along the Income Distribution and the Effects of Monetary Policy. In Research Seminar in International Economics, University of Michigan Working Papers, Number 661.

D'Acunto, F., R. Liu, C. Pflueger, and M. Weber (2018). Flexible prices and leverage. Journal of Financial Economics 129(1), 46-68.

Doepke, M. and M. Schneider (2006). Inflation and the redistribution of nominal wealth. Journal of Political Economy 114(6), 1069-1097.

Farhi, E. and I. Werning (2014). Dilemma not trilemma? Capital controls and exchange rates with volatile capital flows. IMF Economic Review 62(4), 569-605.

Kaplan, G., B. Moll, and G. L. Violante (2017). Monetary policy according to HANK. Technical report, National Bureau of Economic Research.

Nakamura, E. and J. Steinsson (2008). Five facts about prices: A reevaluation of menu cost models. The Quarterly Journal of Economics 123(4), 1415-1464.

Pasten, E., R. Schoenle, and M. Weber (2016). The propagation of monetary policy shocks in a heterogeneous production economy.

Rotemberg, J. J. (1982). Sticky prices in the United States. Journal of Political Economy 90(6), 1187-1211.

Ruggles, S., K. Genadek, R. Goeken, J. Grover, and M. Sobek (2015). American Community Survey. Integrated public use microdata series: Version 6. 
Werning, I. (2015). Incomplete markets and aggregate demand. Technical report, National Bureau of Economic Research. 


\section{Online Appendix}

\section{A Proofs}

\section{A.1 Proposition 1}

Define household $i$ 's total discounted wealth as

$$
y_{i}=\gamma_{i}^{A} \Upsilon_{1}^{A}+\frac{1}{R} \gamma_{i}^{A} \Upsilon_{2}^{A}+p \gamma_{i}^{B} \Upsilon_{1}^{B}+p \frac{1}{R} \gamma_{i}^{B} \Upsilon_{2}^{B}+\frac{b_{i, 1}}{\pi^{A}} .
$$

Then under our proposed perturbation, we have

$$
d y_{i}=\gamma_{i}^{A} d Y_{1}^{A}+p \gamma_{i}^{B} d \Upsilon_{1}^{B}-\left[\frac{1}{R} \gamma_{i}^{A} Y_{2}^{A}+\frac{1}{R} p \gamma_{i}^{B} Y_{2}^{B}\right] \frac{d R}{R}+\left[Y_{1}^{B}+\frac{1}{R} \Upsilon_{2}^{B}\right] \gamma_{i}^{B} d p-\frac{b_{i, 1}}{\pi^{A}} \frac{d \pi^{A}}{\pi^{A}} .
$$

Uncompensated. Define household $i$ 's indirect utility function as

$$
V_{i}\left(R, p, y_{i}\right)=\max U\left(c_{i, 1}\right)+\beta U\left(c_{i, 2}\right)
$$

subject to

$$
p^{\alpha^{i}} c_{i, 1}+\frac{1}{R} p^{\alpha^{i}} c_{i, 2}=y_{i}
$$

This problem implies the two policy functions

$$
c_{i, t}=c_{i, t}\left(R, p, y_{i}\right) .
$$

We will refer to this as the uncompensated or Marshallian demand function of household $i$. To get the partial derivatives of the indirect value function, we start by writing the Lagrangian

$$
L=U\left(c_{i, 1}\right)+\beta U\left(c_{i, 2}\right)+\lambda\left[y_{i}-p^{\alpha^{i}} c_{i, 1}-\frac{1}{R} p^{\alpha^{i}} c_{i, 2}\right], .
$$

where from the first-order condition we have $\lambda=p^{-\alpha^{i}} U^{\prime}\left(c_{i, 1}\right)$. Using the envelope theorem, the partial derivatives can then be written as

$$
\begin{aligned}
& \frac{\partial V_{i}\left(R, p, y_{i}\right)}{\partial R}=\frac{1}{R^{2}} U^{\prime}\left(c_{i, 1}\right) c_{i, 2} \\
& \frac{\partial V_{i}\left(R, p, y_{i}\right)}{\partial p}=-\frac{1}{p} U^{\prime}\left(c_{i, 1}\right) \alpha^{i}\left[c_{i, 1}+\frac{1}{R} c_{i, 2}\right] \\
& \frac{\partial V_{i}\left(R, p, y_{i}\right)}{\partial y_{i}}=p^{-\alpha^{i}} U^{\prime}\left(c_{i, 1}\right) .
\end{aligned}
$$

Compensated. Define household $i^{\prime}$ s expenditure function as

$$
E_{i}(R, p, U)=\min p^{\alpha^{i}} c_{i, 1}+\frac{1}{R} p^{\alpha^{i}} c_{i, 2}
$$


subject to

$$
U\left(c_{i, 1}\right)+\beta U\left(c_{i, 2}\right) \geq U .
$$

This problem gives us the compensated or Hicksian demand functions

$$
c_{i, t}^{c}(R, p, U)
$$

To connect the two, we have the standard identities

$$
c_{i, 1}^{c}(R, p, U)=c_{i, 1}\left(R, p, E_{i}(R, p, U)\right)
$$

To find the partial derivatives, we again write the Lagrangian

$$
L=p^{\alpha^{i}} c_{i, 1}^{c}+\frac{1}{R} p^{\alpha^{i}} c_{i, 2}^{c}+\lambda\left[U-U\left(c_{i, 1}^{c}\right)-\beta U\left(c_{i, 2}^{c}\right)\right],
$$

where $\frac{1}{\lambda}=p^{-\alpha^{i}} U^{\prime}\left(c_{i, 1}^{c}\right)$. By the envelope theorem, we have

$$
\begin{aligned}
& \frac{\partial E_{i}(R, p, U)}{\partial R}=-\frac{1}{R^{2}} p^{\alpha^{i}} c_{i, 2}^{c} \\
& \frac{\partial E_{i}(R, p, U)}{\partial p}=\alpha^{i} p^{\alpha^{i}-1}\left[c_{i, 1}+\frac{1}{R} c_{i, 2}^{c}\right] \\
& \frac{\partial E_{i}(R, p, U)}{\partial U}=p^{\alpha^{i}} \frac{1}{U^{\prime}\left(c_{i, 1}^{c}\right)} .
\end{aligned}
$$

Slutsky equation. Differentiating the identity that links compensated and uncompensated demand, we have

$$
\begin{aligned}
& \frac{\partial c_{i, 1}^{c}}{\partial R}=\frac{\partial c_{i, 1}}{\partial R}+\frac{\partial c_{i, 1}}{\partial y_{i}} E_{R} \\
& \frac{\partial c_{i, 1}^{c}}{\partial p}=\frac{\partial c_{i, 1}}{\partial p}+\frac{\partial c_{i, 1}}{\partial y_{i}} E_{p}
\end{aligned}
$$

Behavioral consumption response. We can now write down household $i$ 's consumption response to our perturbation. We have

$$
d c_{i, 1}=\frac{\partial c_{i, 1}^{c}}{\partial R} d R+\frac{\partial c_{i, 1}^{c}}{\partial p} d p+\frac{\partial c_{i, 1}}{\partial y_{i}}\left[\frac{1}{R} p^{\alpha^{i}} c_{i, 2}^{c} \frac{d R}{R}-\alpha^{i} p^{\alpha^{i}}\left(c_{i, 1}^{c}+\frac{1}{R} c_{i, 2}^{c}\right) \frac{d p}{p}+d y_{i}\right]
$$

Substituting in for $d y_{i}$, the term in square brackets can be written as

$$
\begin{gathered}
\frac{1}{R} p^{\alpha^{i}} c_{i, 2}^{c} \frac{d R}{R}-\alpha^{i} p^{\alpha^{i}}\left(c_{i, 1}^{c}+\frac{1}{R} c_{i, 2}^{c}\right) \frac{d p}{p}+\gamma_{i}^{A} d Y_{1}^{A}+p \gamma_{i}^{B} d Y_{1}^{B} \\
-\left[\frac{1}{R} \gamma_{i}^{A} Y_{2}^{A}+\frac{1}{R} p \gamma_{i}^{B} Y_{2}^{B}\right] \frac{d R}{R}+\left[p Y_{1}^{B}+\frac{1}{R} p Y_{2}^{B}\right] \gamma_{i}^{B} \frac{d p}{p}-\frac{b_{i, 1}}{\pi^{A}} \frac{d \pi^{A}}{\pi^{A}} .
\end{gathered}
$$


We can simplify by using the period 2 budget constraint, to get

$$
b_{i, 2} \frac{d R}{R}+\gamma_{i}^{A} d Y_{1}^{A}+p \gamma_{i}^{B} d Y_{1}^{B}+\left[p \gamma_{i}^{B} Y_{1}^{B}+\frac{1}{R} p \gamma_{i}^{B} Y_{2}^{B}-\alpha^{i} p^{\alpha^{i}}\left(c_{i, 1}+\frac{1}{R} c_{i, 2}\right)\right] \frac{d p}{p}-\frac{b_{i, 1}}{\pi^{A}} \frac{d \pi^{A}}{\pi^{A}}
$$

Note that Auclert (2017) calls $b_{i, 2}$ here unhedged interest rate exposure (URE).

Moreover, define the compensated elasticities

$$
\begin{aligned}
\epsilon_{c, R}^{c} & =\frac{R}{c_{i, 1}} \frac{\partial c_{i, 1}^{c}}{\partial R} \\
\epsilon_{c, p}^{c} & =\frac{p}{c_{i, 1}} \frac{\partial c_{i, 1}^{c}}{\partial p} .
\end{aligned}
$$

And define the marginal propensity to consume as

$$
M P C_{i, 1}=\frac{\partial c_{i, 1}}{\partial y_{i}}
$$

Finally, note that when we normalize $P_{0}^{A}=1$, then $\pi^{A}=P_{1}^{A}=P_{2}^{A}$, and so $\frac{d \pi^{A}}{\pi^{A}}=\frac{d P^{A}}{P^{A}}$. Then we can write

$$
\begin{aligned}
d c_{i, 1}= & c_{i, 1} \epsilon_{c, R}^{c} \frac{d R}{R}+c_{i, 1} \epsilon_{c, p}^{c} \frac{d p}{p}+M P C_{i, 1}\left\{b_{i, 2} \frac{d R}{R}+\gamma_{i}^{A} d Y_{1}^{A}+p \gamma_{i}^{B} d Y_{1}^{B}\right. \\
& \left.+\left[p \gamma_{i}^{B} Y_{1}^{B}+\frac{1}{R} p \gamma_{i}^{B} Y_{2}^{B}-\alpha^{i} p^{\alpha^{i}}\left(c_{i, 1}+\frac{1}{R} c_{i, 2}\right)\right] \frac{d p}{p}-\frac{b_{i, 1}}{\pi^{A}} \frac{d P^{A}}{P^{A}}\right\} .
\end{aligned}
$$

Marginal propensity to consume. We have the Euler equation

$$
U^{\prime}\left(c_{i, 1}\right)=\beta R U^{\prime}\left(c_{i, 2}\right)
$$

Hence,

$$
c_{i, 1}+\frac{1}{R}\left(U^{\prime}\right)^{-1}\left[\frac{U^{\prime}\left(c_{i, 1}\right)}{\beta R}\right]=p^{-\alpha^{i}} y_{i} .
$$

Differentiating with respect to $y_{i}$, we have

$$
\frac{\partial c_{i, 1}}{\partial y_{i}}+\frac{1}{R} \frac{1}{U^{\prime \prime}\left[\left(U^{\prime}\right)^{-1}\left(\frac{U^{\prime}\left(c_{i, 1}\right)}{\beta R}\right)\right]} \frac{1}{\beta R} U^{\prime \prime}\left(c_{i, 1}\right) \frac{\partial c_{i, 1}}{\partial y_{i}}=p^{-\alpha^{i}}
$$

Rewriting this,

$$
M P C_{i, 1}\left[1+\frac{1}{\beta} \frac{U^{\prime \prime}\left(c_{i, 1}\right)}{R^{2} U^{\prime \prime}\left(c_{i, 2}\right)}\right]=p^{-\alpha^{i}} .
$$

Presumably, we would probably actually want to define MPC differently, given that we are counting $c_{i, t}$ and $y_{i}$ in different price indices! Properly, MPC might be better defined to be

$$
M P C_{i, 1} \equiv \frac{\partial}{\partial y_{i}} p^{\alpha^{i}} c_{i, 1}=p^{\alpha^{i}} \frac{\partial c_{i, 1}}{\partial y_{i}}
$$


Under CRRA, once we define MPC as above to account for the right price index, we have

$$
\operatorname{MPC}_{i, 1}\left[1+\frac{1}{R} \frac{c_{i, 2}}{c_{i, 1}}\right]=1
$$

Finally, since there is no behavioral labor supply response in this simple baseline model, we have

$$
M P S_{i, 1}=1-M P C_{i, 1} \text {. }
$$

Hicksian elasticities. Note that, using the Euler equation, we have

$$
U\left(c_{i, 2}\right)=U\left(\left(U^{\prime}\right)^{-1}\left[\frac{U^{\prime}\left(c_{i, 1}\right)}{\beta R}\right]\right) .
$$

The Euler equation holds for the expenditure minimization problem as well. Hence, in the expenditure minimization problem,

$$
U\left(c_{i, 1}^{c}\right)+\beta U\left(\left(U^{\prime}\right)^{-1}\left[\frac{U^{\prime}\left(c_{i, 1}^{c}\right)}{\beta R}\right]\right)=U,
$$

where the policy function is $c_{i, 1}(R, p, U)$. Differentiating with respect to $R$, we have

$$
0=\frac{\partial c_{i, 1}^{c}}{\partial R}\left(U^{\prime}\left(c_{i, 1}^{c}\right)+\beta U^{\prime}\left(c_{i, 2}^{c}\right) \frac{U^{\prime \prime}\left(c_{i, 1}\right)}{U^{\prime \prime}\left(c_{i, 2}\right)} \frac{1}{\beta R}\right)-\beta \frac{U^{\prime}\left(c_{i, 2}^{c}\right)}{U^{\prime \prime}\left(c_{i, 2}\right)} \frac{U^{\prime}\left(c_{i, 1}\right)}{\beta R^{2}} .
$$

Again using CRRA, we have

$$
\begin{aligned}
0 & =\frac{\partial c_{i, 1}^{c}}{\partial R}\left(\left(c_{i, 1}^{c}\right)^{-\gamma}+\beta\left(c_{i, 2}^{c}\right)^{-\gamma} \frac{c_{i, 2}}{c_{i, 1}}\right)-\beta \frac{\left(c_{i, 2}^{c}\right)^{-\gamma}}{-\gamma\left(c_{i, 2}^{c}\right)^{-\gamma-1}} \frac{\left(c_{i, 1}^{c}\right)^{-\gamma}}{\beta R^{2}} \\
& =\frac{\partial c_{i, 1}^{c}}{\partial R}\left(\left(c_{i, 1}^{c}\right)^{-\gamma}+\beta\left(c_{i, 2}^{c}\right)^{-\gamma} \frac{c_{i, 2}}{c_{i, 1}}\right)-\beta \frac{1}{-\gamma\left(c_{i, 2}^{c}\right)^{-1}} \frac{\left(c_{i, 1}^{c}\right)^{-\gamma}}{\beta R^{2}} \\
& =U^{\prime}\left(c_{i, 1}^{c}\right)\left[\frac{\partial c_{i, 1}^{c}}{\partial R}\left(1+\frac{1}{R} \frac{c_{i, 2}^{c}}{c_{i, 1}^{c}}\right)+\frac{\beta}{\gamma} c_{i, 2}^{c} \frac{1}{\beta R^{2}}\right] .
\end{aligned}
$$

Rewriting, we have

$$
\frac{\partial c_{i, 1}^{c}}{\partial R}=-\frac{1}{\gamma} p^{\alpha^{i}} \frac{c_{i, 2}^{c}}{R^{2}} M P C_{i, 1}
$$

Alternatively,

$$
\begin{gathered}
\frac{\partial c_{i, 1}^{c}}{\partial R} \frac{R c_{i, 1}^{c}+c_{i, 2}^{c}}{R c_{i, 1}^{c}}=-\frac{\beta}{\gamma} c_{i, 2}^{c} \frac{1}{\beta R^{2}} \\
M P C=\frac{R c_{i, 1}}{R c_{i, 1}+c_{i, 2}} .
\end{gathered}
$$

And so

$$
1-M P C=\frac{c_{i, 2}}{R c_{i, 1}+c_{i, 2}} .
$$


Thus,

$$
\begin{aligned}
\frac{\partial c_{i, 1}^{c}}{\partial R} \frac{R c_{i, 1}^{c}+c_{i, 2}^{c}}{c_{i, 2}^{c}} & =-\frac{\beta}{\gamma} R c_{i, 1}^{c} \frac{1}{\beta R^{2}} \\
\frac{\partial c_{i, 1}^{c}}{\partial R} & =-\frac{1}{\gamma} \frac{c_{i, 1}^{c}}{R} M P S_{i, 1} .
\end{aligned}
$$

And therefore,

$$
\epsilon_{c, R}^{c}=-\frac{1}{\gamma} M P S_{i, 1}
$$

Similarly, we can write

$$
U\left(c_{i, 1}^{c}\right)+\beta U\left(\left(U^{\prime}\right)^{-1}\left[\frac{U^{\prime}\left(c_{i, 1}^{c}\right)}{\beta R}\right]\right)=U,
$$

where the policy function is $c_{i, 1}(R, p, U)$. Differentiating with respect to $p$, we have

$$
0=\frac{\partial c_{i, 1}^{c}}{\partial p}\left(U^{\prime}\left(c_{i, 1}^{c}\right)+\beta U^{\prime}\left(c_{i, 2}^{c}\right) \frac{U^{\prime \prime}\left(c_{i, 1}\right)}{U^{\prime \prime}\left(c_{i, 2}\right)} \frac{1}{\beta R}\right) .
$$

Since the term in parentheses must be positive, we see that

$$
\frac{\partial c_{i, 1}^{c}}{\partial p}=0
$$

and therefore,

$$
\epsilon_{c, p}^{c}=0
$$

In words, there is no substitution effect due to the change in the relative price $p$. Within the basket $c_{i, t}$ household $i$ substitutes between the two goods but not once we aggregate to the basket level. There is no other such aggregated margin with which $p$ interacts (in the way that $R$ interacts with the inter-temporal substitution margin).

Putting everything together yields the desired result.

\section{A.2 Proposition 2}

We have $Y_{t}^{s}=C_{t}^{s}$ and $Y_{t}=C_{t}$, where $C_{t}=\mathbb{E}_{I}\left(\mu_{i} c_{i, t}\right)$. We assume for now $\mu_{i}=\mu$. Thus,

$$
\begin{aligned}
d C_{1}= & -\frac{1}{\gamma} \mu \mathbb{E}_{I}\left[M P S_{i, 1} c_{i, 1}\right] \frac{d R}{R} \\
& +\mu \mathbb{E}_{I}\left[M P C_{i, 1} b_{i, 2}\right] \frac{d R}{R} \\
& +\mu \mathbb{E}_{I}\left[M P C_{i, 1} \gamma_{i}^{A}\right] d Y_{1}^{A}+p \mathbb{E}_{I}\left[M P C_{i, 1} \gamma_{i}^{B}\right] d Y_{1}^{B} \\
& +\mu \mathbb{E}_{I}\left\{M P C_{i, 1}\left[p \gamma_{i}^{B} Y_{1}^{B}+\frac{1}{R} p \gamma_{i}^{B} Y_{2}^{B}-\alpha^{i} p^{\alpha^{i}}\left(c_{i, 1}+\frac{1}{R} c_{i, 2}\right)\right]\right\} \frac{d p}{p} \\
& -\mu \mathbb{E}_{I}\left[M P C_{i, 1} \frac{b_{i, 1}}{\pi^{A}}\right] \frac{d P^{A}}{P^{A}} .
\end{aligned}
$$


By bond market clearing in both periods, we simply have

$$
\begin{aligned}
d C_{1}= & -\frac{1}{\gamma} \mu \mathbb{E}_{I}\left[M P S_{i, 1} c_{i, 1}\right] \frac{d R}{R} \\
& +\operatorname{Cov}_{I}\left(M P C_{i, 1}, \mu b_{i, 2}\right) \frac{d R}{R} \\
& +\left(\mathbb{E}_{I}\left(M P C_{i, 1}\right)+\mu \operatorname{Cov}_{I}\left(M P C_{i, 1}, \gamma_{i}^{A}\right)\right) d Y_{1}^{A} \\
& +p\left(\mathbb{E}_{I}\left(M P C_{i, 1}\right)+\mu \operatorname{Cov}_{I}\left(M P C_{i, 1}, \gamma_{i}^{B}\right)\right) d Y_{1}^{B} \\
& +\mu \mathbb{E}_{I}\left\{M P C_{i, 1}\left[p \gamma_{i}^{B} Y_{1}^{B}+\frac{1}{R} p \gamma_{i}^{B} Y_{2}^{B}-\alpha^{i} p^{\alpha^{i}}\left(c_{i, 1}+\frac{1}{R} c_{i, 2}\right)\right]\right\} \frac{d p}{p} \\
& -\operatorname{Cov}_{I}\left(M P C_{i, 1}, \frac{\mu b_{i, 1}}{\pi^{A}}\right) \frac{d P^{A}}{P^{A}} .
\end{aligned}
$$

Putting the sectors together,

$$
\begin{aligned}
d C_{1}= & -\frac{1}{\gamma} \mu \mathbb{E}_{I}\left[M P S_{i, 1} c_{i, 1}\right] \frac{d R}{R} \\
& +\operatorname{Cov}_{I}\left(M P C_{i, 1}, \mu b_{i, 2}\right) \frac{d R}{R} \\
& +\sum_{s} \frac{P_{t}^{s}}{P_{t}^{A}}\left(\mathbb{E}_{I}\left(M P C_{i, 1}\right)+\mu \operatorname{Cov}_{I}\left(M P C_{i, 1}, \gamma_{i}^{s}\right)\right) d Y_{1}^{s} \\
& +\left\{p \mathbb{E}_{I}\left[M P C_{i, 1} \mu \gamma_{i}^{B} Y_{1}^{B}\right]+p \frac{1}{R} \mathbb{E}_{I}\left[M P C_{i, 1} \mu \gamma_{i}^{B} Y_{2}^{B}\right]\right. \\
& \left.-\mathbb{E}_{I} \mu\left[M P C_{i, 1} \alpha^{i} p^{\alpha^{i}}\left(c_{i, 1}+\frac{1}{R} c_{i, 2}\right)\right]\right\} \frac{d p}{p} \\
& -\operatorname{Cov}_{I}\left(M P C_{i, 1}, \frac{\mu b_{i, 1}}{\pi^{A}}\right) \frac{d P^{A}}{P^{A}} .
\end{aligned}
$$

Putting the time periods together,

$$
\begin{aligned}
d C_{1}= & -\frac{1}{\gamma} \mu \mathbb{E}_{I}\left[M P S_{i, 1} c_{i, 1}\right] \frac{d R}{R} \\
& +\operatorname{Cov}_{I}\left(M P C_{i, 1}, \mu b_{i, 2}\right) \frac{d R}{R} \\
& +\sum_{s} \frac{P_{t}^{s}}{P_{t}^{A}}\left(\mathbb{E}_{I}\left(M P C_{i, 1}\right)+\mu \operatorname{Cov}_{I}\left(M P C_{i, 1}, \gamma_{i}^{s}\right)\right) d Y_{1}^{s} \\
& +\sum_{t} \frac{1}{R^{t-1}}\left[p\left(\mathbb{E}_{I}\left(M P C_{i, 1}\right)+\mu \operatorname{Cov}_{I}\left(M P C_{i, 1}, \gamma_{i}^{B}\right)\right) Y_{t}^{B}-\mathbb{E}_{I} \mu\left(M P C_{i, 1} \alpha^{i} p^{\alpha^{i}} c_{i, t}\right)\right] \frac{d p}{p} \\
& -\operatorname{Cov}_{I}\left(M P C_{i, 1} \frac{\mu b_{i, 1}}{\pi^{A}}\right) \frac{d P^{A}}{P^{A}} .
\end{aligned}
$$


Therefore, we have

$$
\begin{aligned}
d Y_{1}= & {\left[\operatorname{Cov}_{I}\left(\mathrm{MPC}_{i, 1}, \mu b_{i, 2}\right)-\frac{1}{\gamma} \mu \mathbb{E}_{I}\left(\mathrm{MPS}_{i, 1} c_{i, 1}\right)\right] \frac{d R}{R}-\operatorname{Cov}_{I}\left(\operatorname{MPC}_{i, 1}, \frac{\mu b_{i, 1}}{\pi^{A}}\right) \frac{d P^{A}}{P^{A}} } \\
& +\sum_{s} \frac{P_{t}^{s}}{P_{t}^{A}}\left(\mathbb{E}_{I}\left(\mathrm{MPC}_{i, 1}\right)+\mu \operatorname{Cov}_{I}\left(\mathrm{MPC}_{i, 1}, \gamma_{i}^{s}\right)\right) d Y_{1}^{s} \\
& +\sum_{t} \frac{1}{R^{t-1}}\left[p\left(\mathbb{E}_{I}\left(\mathrm{MPC}_{i, 1}\right)+\mu \operatorname{Cov}_{I}\left(\mathrm{MPC}_{i, 1}, \gamma_{i}^{B}\right)\right) Y_{t}^{B}-\mathbb{E}_{I} \mu\left(\mathrm{MPC}_{i, 1} \alpha^{i} p^{\alpha^{i}} c_{i, t}\right)\right] \frac{d p}{p}
\end{aligned}
$$

\section{A.3 Proposition 3}

To find the aggregate sectoral output response, we have

$$
c_{i, t}^{A}=\left(1-\alpha^{i}\right) p_{t}^{\alpha^{i}} c_{i, t}
$$

and

$$
d C_{1}^{A}=\mathbb{E}_{I}\left(\mu d c_{i, t}^{A}\right)
$$

Now, we have

$$
\begin{aligned}
d c_{i, t}^{A} & =\left(1-\alpha^{i}\right) p_{t}^{\alpha^{i}} d c_{i, t}+\alpha^{i}\left(1-\alpha^{i}\right) p_{t}^{\alpha^{i}-1} c_{i, t} d p \\
& =\frac{c_{i, t}^{A}}{c_{i, t}} d c_{i, t}+\alpha^{i} c_{i, t}^{A} \frac{d p}{p}
\end{aligned}
$$

and

$$
\begin{aligned}
d C_{1}^{A} & =\mathbb{E}_{I}\left(\mu \frac{c_{i, t}^{A}}{c_{i, t}} d c_{i, t}+\mu \alpha^{i} c_{i, t}^{A} \frac{d p}{p}\right) \\
& =\mathbb{E}_{I}\left(\mu\left(1-\alpha^{i}\right) p_{t}^{\alpha^{i}} d c_{i, t}\right)+\left(\alpha C_{1}^{A}+\mu \operatorname{Cov}_{I}\left(\alpha^{i}, c_{i, t}^{A}\right)\right) \frac{d p}{p}
\end{aligned}
$$

where $\alpha=\mathbb{E}_{I}\left(\alpha^{i}\right)$. Even simpler,

$$
\begin{aligned}
C_{t}^{A} & =\mathbb{E}_{I}\left[\left(1-\alpha^{i}\right) p_{t}^{\alpha^{i}}\right] C_{t}+\operatorname{Cov}_{I}\left[\left(1-\alpha^{i}\right) p_{t}^{\alpha^{i}}, \mu c_{i, t}\right] \\
d C_{t}^{A} & =\mathbb{E}_{I}\left[\alpha^{i}\left(1-\alpha^{i}\right) p_{t}^{\alpha^{i}}\right] C_{t} \frac{d p}{p}+\mathbb{E}_{I}\left[\left(1-\alpha^{i}\right) p_{t}^{\alpha^{i}}\right] d C_{t}+d \operatorname{Cov}_{I}\left[\left(1-\alpha^{i}\right) p_{t}^{\alpha^{i}}, \mu c_{i, t}\right]
\end{aligned}
$$

We have

$$
d c_{i, 1}^{A}=\alpha^{i} c_{i, 1}^{A} \frac{d p}{p}+\left(1-\alpha^{i}\right) p_{1}^{\alpha^{i}} d c_{i, t}
$$

And thus

$$
\begin{aligned}
d C_{1}^{A} & =\mathbb{E}_{I}\left(\mu \alpha^{i} c_{i, 1}^{A}\right) \frac{d p}{p}+\mathbb{E}_{I}\left[\mu\left(1-\alpha^{i}\right) p_{1}^{\alpha^{i}} d c_{i, t}\right] \\
& =\mathbb{E}_{I}\left(\mu \alpha^{i} c_{i, 1}^{A}\right) \frac{d p}{p}+\mathbb{E}_{I}\left[\left(1-\alpha^{i}\right) p_{1}^{\alpha^{i}}\right] d C_{1}+\mu \operatorname{Cov}_{I}\left[\left(1-\alpha^{i}\right) p_{1}^{\alpha^{i}}, d c_{i, t}\right]
\end{aligned}
$$


Alternatively, we have

$$
\begin{aligned}
d c_{i, 1}^{A}= & \alpha^{i} c_{i, 1}^{A} \frac{d p}{p}-\frac{1}{\gamma} M P S_{i, 1} c_{i, 1}^{A} \frac{d R}{R}+\left(1-\alpha^{i}\right) p_{1}^{\alpha^{i}} M P C_{i, 1}\left\{b_{i, 2} \frac{d R}{R}+\gamma_{i}^{A} d Y_{1}^{A}+p \gamma_{i}^{B} d Y_{1}^{B}\right. \\
& \left.\left.+\left[p \gamma_{i}^{B} Y_{1}^{B}+\frac{1}{R} p \gamma_{i}^{B} Y_{2}^{B}-\alpha^{i} p^{\alpha^{i}}\left(c_{i, 1}+\frac{1}{R} c_{i, 2}\right)\right] \frac{d p}{p}-\frac{b_{i, 1}}{\pi^{A}} \frac{d P^{A}}{P^{A}}\right\}\right\} .
\end{aligned}
$$

Define (as before)

$$
\begin{aligned}
& M P C_{i, 1} \equiv p_{1}^{\alpha^{i}} \frac{\partial c_{i, 1}}{\partial y_{i}} \\
& M \hat{P} C_{i, 1}^{A} \equiv\left(1-\alpha^{i}\right) p_{1}^{\alpha^{i}} M P C_{i, 1}=\left(1-\alpha^{i}\right) \frac{\partial c_{i, 1}}{\partial y_{i}}=p_{t}^{-\alpha^{i}} \frac{\partial c_{i, 1}^{A}}{\partial y_{i}}
\end{aligned}
$$

In words, $M \hat{P} C_{i, 1}^{A}$ is the marginal propensity to consume good $A$ when...

Then we have

$$
\begin{aligned}
d c_{i, 1}^{A}= & \alpha^{i} c_{i, 1}^{A} \frac{d p}{p}-\frac{1}{\gamma} M P S_{i, 1} c_{i, 1}^{A} \frac{d R}{R}+M \hat{P} C_{i, 1}^{A}\left\{b_{i, 2} \frac{d R}{R}+\gamma_{i}^{A} d Y_{1}^{A}+p \gamma_{i}^{B} d Y_{1}^{B}\right. \\
& \left.\left.+\left[p \gamma_{i}^{B} Y_{1}^{B}+\frac{1}{R} p \gamma_{i}^{B} Y_{2}^{B}-\alpha^{i} p^{\alpha^{i}}\left(c_{i, 1}+\frac{1}{R} c_{i, 2}\right)\right] \frac{d p}{p}-\frac{b_{i, 1}}{\pi^{A}} \frac{d P^{A}}{P^{A}}\right\}\right\}
\end{aligned}
$$

And therefore,

$$
\begin{aligned}
d Y_{1}^{A}= & {\left[\operatorname{Cov}_{I}\left(\mathrm{MPC}_{i, 1}, \mu b_{i, 2}\right)-\frac{1}{\gamma} \mu \mathbb{E}_{I}\left(\mathrm{MPS}_{i, 1} c_{i, 1}^{A}\right)\right] \frac{d R}{R}-\operatorname{Cov}_{I}\left(\mathrm{MPC}_{i, 1} \frac{\mu b_{i, 1}}{\pi^{A}}\right) \frac{d P^{A}}{P^{A}} } \\
& +\sum_{s} \frac{P_{t}^{s}}{P_{t}^{A}}\left(\mathbb{E}_{I}\left(\mathrm{MPC}_{i, 1}\right)+\mu \operatorname{Cov}_{I}\left(\mathrm{MPC}_{i, 1}, \gamma_{i}^{s}\right)\right) d Y_{1}^{s}+\mathbb{E}_{I}\left(\mu \alpha^{i} c_{i, 1}^{A}\right) \frac{d p}{p} \\
& +\sum_{t} \frac{1}{R^{t-1}}\left[p\left(\mathbb{E}_{I}\left(\mathrm{MPC}_{i, 1}\right)+\mu \operatorname{Cov}_{I}\left(\mathrm{MPC}_{i, 1}, \gamma_{i}^{B}\right)\right) Y_{t}^{B}-\mathbb{E}_{I} \mu\left(\mathrm{MPC}_{i, 1} \alpha^{i} p^{\alpha^{i}} c_{i, t}\right)\right] \frac{d p}{p}
\end{aligned}
$$

Also, we can rewrite this as

$$
\begin{aligned}
d Y_{1}^{A} & =\mathbb{E}_{I}\left(\mu d c_{i, 1}^{A}\right) \\
& =\mathbb{E}_{I}\left[\mu \alpha^{i} c_{i, 1}^{A} \frac{d p}{p}+\mu\left(1-\alpha^{i}\right) p_{1}^{\alpha^{i}} d c_{i, 1}\right] \\
& =\mathbb{E}_{I}\left(\mu \alpha^{i} c_{i, 1}^{A}\right) \frac{d p}{p}+\mathbb{E}_{I}\left[\mu\left(1-\alpha^{i}\right) p_{1}^{\alpha^{i}} d c_{i, 1}\right] \\
& =\mathbb{E}_{I}\left[\mu\left(1-\alpha^{i}\right) p_{1}^{\alpha^{i}}\right] d Y_{1}+\mathbb{E}_{I}\left[\mu \alpha^{i}\left(1-\alpha^{i}\right) p^{\alpha^{i}} c_{i, 1}\right] \frac{d p}{p}+\mu \operatorname{Cov}_{I}\left[\left(1-\alpha^{i}\right) p_{1}^{\alpha^{i}}, d c_{i, 1}\right] .
\end{aligned}
$$




\section{B A two-agent, two-sector New Keynesian model}

In this appendix, we present a simplified version of infinite-horizon model in the spirit of the standard New Keynesian framework. Relative to the standard model, we make two key extensions. First, we introduce a second household type who we assume is hand-to-mouth. Second, we introduce a second production sector. We refer to the two households as College and Non-College. The former is of mass $(1-\mu)$, the latter of mass $\mu$. We furthermore assume that College households only work in sector $A$ and Non-College only work in sector $B$. Finally, we will solve this model under perfect foresight.

\section{B.1 Households}

We assume that household $i \in\{C, N C\}$ has preferences given by

$$
\sum_{t=0}^{\infty} \beta^{t}\left[u\left(C_{i, t}\right)-v\left(N_{i, t}\right)\right]
$$

where the consumption bundle is given by

$$
C_{i, t}=\left(C_{i, t}^{A}\right)^{1-\alpha^{i}}\left(C_{i, t}^{B}\right)^{\alpha^{i}}
$$

with

$$
C_{i, t}^{S}=\left(\int_{0}^{1} C_{i, t}^{S}(j)^{\frac{\epsilon-1}{\epsilon}} d j\right)^{\frac{\epsilon}{\epsilon-1}}
$$

where $s \in\{A, B\}$ and $j$ refers to the intermediate good producer $j$ in sector $s$.

College households' nominal budget constraints are given by

$$
P_{t}^{A} C_{C, t}^{A}+P_{t}^{B} C_{C, t}^{B}+B_{C, t+1} \leq W_{C, t} N_{C, t}+\left(1+i_{t}\right) B_{C, t}+T_{C, t}
$$

where $T_{i, t}$ is a set of lump-sum transfers, including firm profits, $W_{i, t}$ is the wage rate paid to household $i$ (in the sector where $i$ works), and $P_{t}^{s}$ is the price index in sector $s$. College households can trade a nominal bond, $B_{C, t+1}$, which pays a rate of interest $1+i_{t+1}$. The bond is in zero net supply so that in equilibrium no household ever holds a nonzero asset position.

We assume that Non-College households behave hand-to-mouth. Therefore, their budget constraints are given by

$$
P_{t}^{A} C_{N C, t}^{A}+P_{t}^{B} C_{N C, t}^{B} \leq W_{N C, t} N_{N C, t}+T_{N C, t} .
$$

Assumption. (Bond returns) We assume (or rather normalize) that bonds pay in terms of College households' consumption basket. We will denote the representative College household's real bond position as $P_{C, t} b_{C, t+1}=B_{C, t+1}$.

The standard cost minimization problems imply the following demand functions as well as household 
$i$ 's consumer price index

$$
\begin{aligned}
& C_{i, t}^{A}=\left(1-\alpha^{i}\right) \frac{P_{i, t}}{P_{t}^{A}} C_{i, t} \\
& C_{i, t}^{B}=\alpha^{i} \frac{P_{i, t}}{P_{t}^{B}} C_{i, t} \\
& P_{i, t}=\left(P_{t}^{A}\right)^{1-\alpha^{i}}\left(P_{t}^{B}\right)^{\alpha^{i}} .
\end{aligned}
$$

The real budget constraint of the representative College household can thus be written as

$$
C_{C, t}+b_{C, t+1}=\frac{W_{C, t}}{P_{C, t}} N_{C, t}+\frac{1+i_{t}}{1+\pi_{C, t}} b_{C, t}+\frac{T_{C, t}}{P_{C, t}}
$$

where $1+\pi_{C, t}=P_{C, t} / P_{C, t-1}$. Similarly, the budget constraint for the Non-College household is given by

$$
C_{N C, t}=\frac{W_{N C, t}}{P_{N C, t}} N_{N C, t}+\frac{T_{N C, t}}{P_{N C, t}}
$$

so that the Non-College household always consumes all income, which comes from labor and a government transfer.

The associated first-order conditions can thus be written as

$$
\begin{aligned}
u^{\prime}\left(C_{C, t}\right) & =\beta \frac{1+i_{t+1}}{1+\pi_{C, t+1}} u^{\prime}\left(C_{C, t+1}\right) \\
v^{\prime}\left(C_{C, t}\right) & =\frac{W_{C, t}}{P_{C, t}} u^{\prime}\left(C_{C, t}\right) \\
v^{\prime}\left(C_{N C, t}\right) & =\frac{W_{N C, t}}{P_{N C, t}} u^{\prime}\left(C_{N C, t}\right) .
\end{aligned}
$$

\section{B.2 Firms}

The economy comprises two production sectors, $A$ and $B$. The final consumption good in each sector is assembled from a continuum of intermediate varieties according to the production function

$$
Y_{t}^{S}=\left(\int_{0}^{1} Y_{t}^{S}(j)^{\frac{\epsilon-1}{\epsilon}} d j\right)^{\frac{\epsilon}{\epsilon-1}}
$$

for $s \in\{A, B\}$.

Each intermediate variety $j$ in production sector $s$ is produced by a single intermediate producer which we will refer to as firm $j$ in sector $s$. Firm $j$ 's production function is given by

$$
Y_{t}^{S}(j)=A_{t} N_{t}^{s}(j)
$$

Firm $j$ is monopolistically competitive and sets the price on its differentiated variety, $P_{t}^{s}(j)$. Its total profits in period $t$ are given by

$$
\Pi_{t}^{s}(j)=P_{t}^{s}(j) Y_{t}^{s}(j)-\left(1-\tau^{L}\right) W_{t}^{s} N_{t}^{s}(j),
$$


where $\tau^{L}$ is an employment subsidy and $W_{t}^{s}$ is the nominal wage rate offered in sector $s$. We can write firm $j$ 's real marginal cost as

$$
M C_{t}^{s}=\frac{1-\tau^{L}}{A_{t}} \frac{W_{t}^{s}}{P_{t}^{s}}
$$

so that each firm $j$ in sector $s$ faces the same marginal cost.

Price-setting under flexible prices. If firm $j$ can set prices flexibly each period, then we have from the profit condition

$$
P_{t}^{s}(j)=\frac{\epsilon}{\epsilon-1} M C_{t}^{s} P_{t}^{s} .
$$

In steady state, we will have $P_{t}^{s}(j)=P_{t}^{s}$. The above condition then directly implies that the steady state real marginal cost is given by the inverse of the markup, $M C^{s}=\frac{\epsilon-1}{\epsilon}$.

Price-setting under Calvo. We now assume that a fraction $1-\delta^{s}$ of firms in sector $s$ can reset their prices in every period. The optimality criterion for firm $j$ to reset its price in period $t$ can then be written as

$$
\sum_{k=0}^{\infty}\left(\delta^{s}\right)^{k} R_{t, k}\left[\bar{P}_{t}^{s}(j)^{1-\epsilon}\left(P_{t+k}^{s}\right)^{\epsilon} Y_{t+k}-\bar{P}_{t}^{s}(j)^{-\epsilon}\left(P_{t+k}^{s}\right)^{1-\epsilon} Y_{t+k}^{s} M C_{t+k}^{s}\right]
$$

where $\bar{P}_{t}^{s}(j)$ is firm $j$ 's reset price. The first-order condition can be written as

$$
\sum_{k=0}^{\infty}\left(\delta^{s}\right)^{k} R_{t, k}\left[(1-\epsilon) \bar{P}_{t}^{s}(j)^{-\epsilon}\left(P_{t+k}^{s}\right)^{\epsilon} Y_{t+k}+\epsilon \bar{P}_{t}^{s}(j)^{-\epsilon-1}\left(P_{t+k}^{s}\right)^{1-\epsilon} Y_{t+k}^{s} M C_{t+k}^{s}\right]=0,
$$

where $R_{t, k}=\prod_{h=0}^{k} \frac{1}{1+i_{t+h}}$ is firm $j^{\prime}$ s discount factor since we abstract from uncertainty.

The Phillips Curve in sector $s$. To derive the canonical New Keynesian Phillips Curve for sector $s$, we begin by linearizing equation (B.11). We will discuss our steady state selection in detail later but can already anticipate that it will feature zero inflation in both sectors. Since firms are symmetric in steady state, we have $P^{s}(j)=P^{s}$. Generally, we drop time subscripts to denote steady state variables. Finally, we denote by lower-case letters the log deviations of a variable from the zero-inflation steady state, so that $x_{t}=\ln \left(X_{t}\right)-\ln (X)$.

Linearizing yields

$$
\bar{p}_{t}^{s}(j)=\left(1-\delta^{s} \beta\right) \sum_{k=0}^{\infty}\left(\delta^{s} \beta\right)^{k}\left(p_{t+k}^{s}+m c_{t+k}^{s}\right) .
$$

Recalling the definition of the price index of sector $s$, we can rewrite it as

$$
P_{t}^{s}=\left[\left(1-\delta^{s}\right) \bar{P}_{t}^{s}(j)^{1-\epsilon}+\delta^{S}\left(P_{t-1}^{s}\right)^{1-\epsilon}\right]^{\frac{1}{1-\epsilon}}
$$

because conditional on resetting prices, each firm $j$ chooses a symmetric reset price. Linearizing this equation, we have

$$
p_{t}^{S}=\left(1-\delta^{S}\right) \bar{p}_{t}^{S}(j)+\delta^{s} p_{t-1}^{s}
$$


Hence, we can substitute for $\bar{p}_{t}^{s}(j)$ and obtain

$$
\begin{aligned}
p_{t}^{s}-\delta^{s} p_{t-1}^{s} & =\left(1-\delta^{s}\right)\left(1-\delta^{s} \beta\right) \sum_{k=0}^{\infty}\left(\delta^{s} \beta\right)^{k}\left(p_{t+k}^{s}+m c_{t+k}^{s}\right) \\
& =\left(1-\delta^{s}\right)\left(1-\delta^{s} \beta\right)\left[p_{t}^{s}+m c_{t}^{s}+\sum_{k=1}^{\infty}\left(\delta^{s} \beta\right)^{k}\left(p_{t+k}^{s}+m c_{t+k}^{s}\right]\right. \\
& =\left(1-\delta^{s}\right)\left(1-\delta^{s} \beta\right)\left(p_{t}^{s}+m c_{t}^{s}\right)+p_{t+1}^{s}-\delta^{s} p_{t}^{s} .
\end{aligned}
$$

Define sector-s inflation as $\pi_{t}^{s}=p_{t}^{s}-p_{t-1}^{s}$, we can write the Phillips Curve for sector $s$ as

$$
\pi_{t}^{s}=\theta^{s} m c_{t}^{s}+\beta \pi_{t+1}^{s},
$$

where $\theta^{s}=\frac{\left(1-\delta^{s}\right)\left(1-\delta^{s} \beta\right)}{\delta^{s}}$.

Marginal cost. Before moving on, it would be useful to linearize our equation for real marginal cost in sector $s$. We have

$$
m c_{t}^{s}=w_{t}^{s}-p_{t}^{s}-a_{t}
$$

Unlike in the standard NK model, there is no single consumer price index for the economy. As a result, we cannot rewrite the linearized equations in terms of a CPI as is standard.

\section{B.3 Market clearing, resource constraint and labor supply}

Since we are considering a closed economy model, the resource constraint is trivially

$$
Y_{t}^{s}=(1-\mu) C_{C, t}^{s}+\mu C_{N C, t}^{s} .
$$

The labor market clearing conditions are given by

$$
\begin{aligned}
& N_{t}^{A}(j)=(1-\mu) N_{C, t}(j) \\
& N_{t}^{B}(j)=\mu N_{N C, t}(j)
\end{aligned}
$$

at the firm level. To derive aggregate labor supply, we have

$$
\begin{aligned}
A_{t} N_{t}^{s}(j) & =Y_{t}^{s}(j) \\
& =\left(\frac{P_{t}^{s}(j)}{P_{t}^{s}}\right)^{-\epsilon} Y_{t}^{s} \\
\int_{0}^{1} A_{t} N_{t}^{s}(j) d j & =\int_{0}^{1}\left(\frac{P_{t}^{s}(j)}{P_{t}^{s}}\right)^{-\epsilon} Y_{t}^{s} d j,
\end{aligned}
$$

and finally arrive at

$$
A_{t} N_{t}^{s}=Y_{t}^{s} \int_{0}^{1}\left(\frac{P_{t}^{s}(j)}{P_{t}^{S}}\right)^{-\epsilon} d j .
$$

We denote this dispersion measure by $D_{t}^{s}$.

Similarly, we have the wage rate equivalences $W_{C, t}=W_{t}^{A}$ and $W_{N C, t}=W_{t}^{B}$. By Walras' law, we can drop one of these constraints. 


\section{B.4 Equilibrium conditions}

We begin by stating the set of equilibrium conditions of our model. Then we solve for the steady state, and finally we linearize the equilibrium conditions. This gives us the (IS) and (NKPC) equations of our model.

Simplifying assumptions. In this section, we start by considering an initialization where neither household holds positive assets. Furthermore, we assume that profits are rebated symmetrically at the household level. Finally, we use CRRA utility.

We also define the notion of relative price now, which will be a key variable:

$$
p_{t}=\frac{P_{t}^{B}}{P_{t}^{A}}
$$

We have

$$
\begin{aligned}
\frac{P_{t}^{A}}{P_{i, t}} & =\frac{P_{t}^{A}}{\left(P_{t}^{A}\right)^{1-\alpha^{i}}\left(P_{t}^{B}\right)^{\alpha^{i}}}=\left(\frac{P_{t}^{A}}{P_{t}^{B}}\right)^{\alpha^{i}}=p_{t}^{-\alpha^{i}} \\
\frac{P_{t}^{B}}{P_{i, t}} & =\frac{P_{t}^{B}}{\left(P_{t}^{A}\right)^{1-\alpha^{i}}\left(P_{t}^{B}\right)^{\alpha^{i}}}=\left(\frac{P_{t}^{B}}{P_{t}^{A}}\right)^{1-\alpha^{i}}=p_{t}^{1-\alpha^{i}} \\
\frac{P_{N C, t}}{P_{C, t}} & =\frac{\left(P_{t}^{A}\right)^{1-\alpha^{N C}}\left(P_{t}^{B}\right)^{\alpha^{N C}}}{\left(P_{t}^{A}\right)^{1-\alpha^{C}}\left(P_{t}^{B}\right)^{\alpha^{C}}}=\left(P_{t}^{A}\right)^{\alpha^{C}-\alpha^{N C}}\left(P_{t}^{B}\right)^{\alpha^{N C}-\alpha^{C}}=p_{t}^{\alpha^{N C}-\alpha^{C}}
\end{aligned}
$$

Lastly, we now introduce notation for real wages. We define

$$
w_{i, t}=\frac{W_{i, t}}{P_{i, t}}
$$

Letting profit rebates to households be given by,

$$
T_{t}=\sum_{s} P_{t}^{s} Y_{t}^{s}-W_{t}^{s} N_{t}^{s}
$$

the two household budget constraints become

$$
\begin{aligned}
C_{C, t} & =\frac{W_{C, t}}{P_{C, t}} N_{C, t}+\frac{1}{P_{C, t}}\left[P_{t}^{A} Y_{t}^{A}-W_{C, t}(1-\mu) N_{C, t}+P_{t}^{B} Y_{t}^{B}-W_{N C, t} \mu N_{N C, t}\right] \\
C_{N C, t} & =\frac{W_{N C, t}}{P_{N C, t}} N_{N C, t}+\frac{1}{P_{N C, t}}\left[P_{t}^{A} Y_{t}^{A}-W_{C, t}(1-\mu) N_{C, t}+P_{t}^{B} Y_{t}^{B}-W_{N C, t} \mu N_{N C, t}\right]
\end{aligned}
$$

or

$$
\begin{gathered}
P_{C, t} C_{C, t}=P_{t}^{A} Y_{t}^{A}+P_{t}^{B} Y_{t}^{B}+\mu\left[W_{C, t} N_{C, t}-W_{N C, t} N_{N C, t}\right] \\
P_{N C, t} C_{N C, t}=P_{t}^{A} Y_{t}^{A}+P_{t}^{B} Y_{t}^{B}+(1-\mu)\left[W_{N C, t} N_{N C, t}-W_{C, t} N_{C, t}\right] .
\end{gathered}
$$


In terms of the relative price, the complete set of equilibrium conditions can thus be written as

$$
\begin{aligned}
D_{t}^{A} Y_{t}^{A} & =(1-\mu) A_{t} N_{C, t} \\
D_{t}^{B} Y_{t}^{B} & =\mu A_{t} N_{N C, t} \\
Y_{t}^{A} & =(1-\mu)\left(1-\alpha^{C}\right) p_{t}^{\alpha^{C}} C_{C, t}+\mu\left(1-\alpha^{N C}\right) p_{t}^{\alpha^{N C}} C_{N C, t} \\
Y_{t}^{B} & =(1-\mu) \alpha^{C} p_{t}^{-\left(1-\alpha^{C}\right)} C_{C, t}+\mu \alpha^{N C} p_{t}^{-\left(1-\alpha^{N C}\right)} C_{N C, t} \\
C_{C, t}^{-\gamma} & =\beta \frac{1+i_{t+1}}{1+\pi_{C, t+1}} C_{C, t+1}^{-\gamma} \\
N_{C, t}^{\phi} & =w_{C, t} C_{C, t}^{-\gamma} \\
N_{N C, t}^{\phi} & =w_{N C, t} C_{N C, t}^{-\gamma} \\
C_{C, t} & =p_{t}^{-\alpha^{C}} Y_{t}^{A}+p_{t}^{1-\alpha^{C}} Y_{t}^{B}+\mu\left[w_{C, t} N_{C, t}-w_{N C, t} p_{t}^{\alpha^{N C}-\alpha^{C}} N_{N C, t}\right] \\
C_{N C, t} & =p_{t}^{-\alpha^{N C}} Y_{t}^{A}+p_{t}^{1-\alpha^{N C}} Y_{t}^{B}+(1-\mu)\left[w_{N C, t} N_{N C, t}-w_{C, t} p_{t}^{\alpha^{C}-\alpha^{N C}} N_{C, t}\right] \\
\pi_{t}^{s} & =\theta^{s} m C_{t}^{s}+\beta \pi_{t+1}^{s} \\
M C_{t}^{A} & =\left(1-\tau^{L}\right) \frac{w_{C, t}}{A_{t}} p_{t}^{\alpha^{C}} \\
M C_{t}^{B} & =\left(1-\tau^{L}\right) \frac{w_{N C, t}}{A_{t}} p_{t}^{-\left(1-\alpha^{N C}\right)} .
\end{aligned}
$$

\section{B.5 Steady state}

Throughout, we drop time subscripts to denote the steady state. We set $\mu=1 / 2$ and $\left(1-\alpha^{C}\right)=\alpha^{N C}$ to ensure that the steady state will be symmetric. To simplify notation, let $\alpha=\alpha^{C}=\left(1-\alpha^{N C}\right)$. Finally, we set $A=1$.

We will restrict attention to a steady state where inflation is zero in both production sectors. We conjecture that the relative price in steady state, given our assumptions on parameters, is 1 , and we will verify this later. That is,

$$
M C^{s}=M C=\frac{\epsilon-1}{\epsilon},
$$

and then with $\tau^{L}=1 / \epsilon$, we have

$$
w_{i}=w=1
$$

Similarly,

$$
1+i=\frac{1}{\beta} .
$$

The way we have set this up, it should be globally efficient to set $C_{C}=C_{N C}$ for the planner in steady state, as well as $N_{C}=N_{N C}$. That is, we have engineered an efficient symmetric steady state. In particular, we will have

$$
2 Y^{A}=2 Y^{B}=C_{C}=C_{N C}=N_{C}=N_{N C}=w=1 .
$$


We can easily confirm that all other equilibrium conditions are consistent with this steady state allocation. And it's almost surely the efficient one from a social planner's perspective.

\section{B.6 Linearizing the equilibrium conditions}

We now linearize each of the equilibrium conditions. To do so, we switch to continuous time. We begin by defining some useful notation.

Notation. For all variables $X_{t}$, we drop the time subscripts and denote by $X$ the steady state value of $X_{t}$ as we have already done in the previous subsection. We define $x_{t}=\ln \left(X_{t}\right)-\ln (X)$. Furthermore, we will define the natural allocation as the flexible price allocation and denote it by $\tilde{X}_{t}$. In log deviations, we write $\tilde{x}_{t}=\ln \left(\tilde{X}_{t}\right)-\ln (X)$.

Finally, while we use inflation variables in their level form, we linearize the interest rate. Abusing notation, we will subsequently denote by $i_{t}+i$ the actual level of the interest rate, where $i_{t}$ now denotes the level deviation from steady state. We also abuse notation to denote by $p_{t}=\ln \left(p_{t}^{\text {level }}\right)-\ln (p)$, where $\ln (p)=0$.

Labor-leisure condition. We have

$$
\begin{aligned}
& \gamma c_{i, t}+\phi n_{i, t}=w_{i, t} \\
& \gamma \tilde{c}_{i, t}+\phi \tilde{n}_{i, t}=\tilde{w}_{i, t} .
\end{aligned}
$$

HtM budget constraint. We have

$$
\begin{aligned}
C_{N C}\left(1+c_{N C, t}\right)= & p^{-\alpha^{N C}} Y^{A}\left(1-(1-\alpha) p_{t}+y_{t}^{A}\right)+p^{1-\alpha^{N C}} Y^{B}\left(1+\alpha p_{t}+y_{t}^{B}\right) \\
& +(1-\mu) w N\left[w_{N C, t}+n_{N C, t}-w_{C, t}-\left(\alpha^{C}-\alpha^{N C}\right) p_{t}-n_{C, t}\right] .
\end{aligned}
$$

Simplifying

$$
\begin{aligned}
c_{N C, t}= & \frac{1}{2} p_{t}-\alpha p_{t}+(2 \alpha \mu-\mu) p_{t}+\frac{1}{2} y_{t}^{A}+\frac{1}{2} y_{t}^{B} \\
& +(1-\mu)\left[w_{N C, t}+n_{N C, t}-w_{C, t}-n_{C, t}\right] .
\end{aligned}
$$

Using $\mu=\frac{1}{2}$, we have

$$
c_{N C, t}=\frac{1}{2} y_{t}^{A}+\frac{1}{2} y_{t}^{B}+\frac{1}{2}\left[w_{N C, t}+n_{N C, t}-w_{C, t}-n_{C, t}\right]
$$

Euler equation. We first show how to transform the Euler equation into continuous time. The Euler equation is given by

$$
\left(\frac{C_{C, t+1}}{C_{C, t}}\right)^{\gamma}=\beta \frac{1+i_{t+1}}{1+\pi_{C, t+1}} .
$$

In the document NK3, we show that this can be written in continuous time as

$$
\frac{\dot{C}_{C, t}}{C_{C, t}}=\frac{1}{\gamma}\left(i_{t}-\pi_{C, t}-\rho\right) \text {. }
$$


To log-linearize, let $\dot{c}_{C, t}=\frac{d}{d t} C_{C, t}=\frac{d}{d t}\left(\log C_{C, t}-\log C_{C}\right)$, and so

$$
\dot{c}_{C, t}=\frac{i+i_{t}-\pi_{C, t}-\rho}{\gamma}
$$

where we now also linearized the interest rate around its steady state level. In steady state, we have $i=\rho$, since $\beta(1+i)=1$ and thus $\log (\beta)+i=0$. Therefore we have

$$
\dot{c}_{C, t}=\frac{1}{\gamma}\left(i_{t}-\pi_{C, t}\right) .
$$

Resource constraint. We have

$$
\begin{aligned}
& Y^{A}\left(1+y_{t}^{A}\right)=(1-\mu)\left(1-\alpha^{C}\right) p^{\alpha^{C}} C_{C}\left(1+\alpha^{C} p_{t}+c_{C, t}\right)+\mu\left(1-\alpha^{N C}\right) p^{\alpha^{N C}} C_{N C}\left(1+\alpha^{N C} p_{t}+c_{N C, t}\right) \\
& Y^{B}\left(1+y_{t}^{B}\right)=(1-\mu) \alpha^{C} p^{-\left(1-\alpha^{C}\right)} C_{C}\left(1-\left(1-\alpha^{C}\right) p_{t}+c_{C, t}\right)+\mu \alpha^{N C} p^{-\left(1-\alpha^{N C}\right)} C_{N C}\left(1-\left(1-\alpha^{N C}\right) p_{t}+c_{N C, t}\right) .
\end{aligned}
$$

Noting $\alpha=\alpha^{C}=\left(1-\alpha^{N C}\right), p=1$ and $Y^{s}=C_{i}=1$, we have

$$
\begin{aligned}
& y_{t}^{A}=p_{t}+c_{C, t}+c_{N C, t} \\
& y_{t}^{B}=-p_{t}+c_{C, t}+c_{N C, t} .
\end{aligned}
$$

Labor market clearing. We have

$$
\begin{aligned}
D_{t}^{A} Y_{t}^{A} & =(1-\mu) A_{t} N_{C, t} \\
D_{t}^{B} Y_{t}^{B} & =\mu A_{t} N_{N C, t},
\end{aligned}
$$

where to first order around the zero-inflation steady state, the price dispersion term drops out. Hence,

$$
\begin{aligned}
& y_{t}^{A}=a_{t}+n_{C, t} \\
& y_{t}^{B}=a_{t}+n_{N C, t} .
\end{aligned}
$$

Marginal cost and Phillips Curve. We have

$$
\begin{aligned}
\pi_{t}^{s} & =\theta^{s} m c_{t}^{s}+\beta \pi_{t+1}^{s} \\
m c_{t}^{A} & =w_{C, t}-a_{t}+\alpha p_{t} \\
m c_{t}^{B} & =w_{N C, t}-a_{t}-\alpha p_{t} .
\end{aligned}
$$

In continuous time, we have

$$
\dot{\pi}_{t}^{s}=\rho \pi_{t}^{s}-\frac{\theta^{s}}{1+\rho} m c_{t}^{s} .
$$




\section{B.7 Phillips Curves and IS Equations}

In summary, we have

$$
\begin{aligned}
y_{t}^{A} & =a_{t}+n_{C, t} \\
y_{t}^{B} & =a_{t}+n_{N C, t} \\
y_{t}^{A} & =p_{t}+c_{C, t}+c_{N C, t} \\
y_{t}^{B} & =-p_{t}+c_{C, t}+c_{N C, t} \\
\gamma c_{i, t}+\phi n_{i, t} & =w_{i, t} \\
c_{N C, t} & =\frac{1}{2} y_{t}^{A}+\frac{1}{2} y_{t}^{B}+\frac{1}{2}\left[w_{N C, t}+n_{N C, t}-w_{C, t}-n_{C, t}\right] \\
m c_{t}^{A} & =w_{C, t}-a_{t}+\alpha p_{t} \\
m c_{t}^{B} & =w_{N C, t}-a_{t}-\alpha p_{t} \\
\dot{\pi}_{t}^{s} & =\rho \pi_{t}^{s}-\frac{\theta^{s}}{1+\rho} m c_{t}^{s} \\
\dot{c}_{C, t} & =\frac{1}{\gamma}\left(i_{t}-\pi_{C, t}\right) .
\end{aligned}
$$

Lemma 5. The relative price now determines the relative consumption responses of households. We have

$$
d c_{N C, t}=2 \frac{1+\phi}{\gamma} d p_{t}+\frac{\gamma-2}{\gamma} d c_{C, t} .
$$

We can now solve the Phillips curves

$$
\begin{aligned}
& \dot{\pi}_{t}^{A}=\rho \pi_{t}^{A}-\frac{\theta^{A}}{1+\rho}\left((\gamma+\phi) c_{C, t}+(\phi+\alpha) p_{t}+\phi c_{N C, t}-(1+\phi) a_{t}\right) \\
& \dot{\pi}_{t}^{B}=\rho \pi_{t}^{B}-\frac{\theta^{B}}{1+\rho}\left((\gamma+\phi) c_{N C, t}-(\phi+\alpha) p_{t}+\phi c_{C, t}-(1+\phi) a_{t}\right)
\end{aligned}
$$

and plugging in

$$
\begin{aligned}
& \dot{\pi}_{t}^{A}=\rho \pi_{t}^{A}-\frac{\theta^{A}}{1+\rho}\left(\frac{\gamma^{2}+2 \phi \gamma-2 \phi}{\gamma} c_{C, t}+\frac{\gamma \phi+\gamma \alpha+2 \phi+2 \phi^{2}}{\gamma} p_{t}-(1+\phi) a_{t}\right) \\
& \dot{\pi}_{t}^{B}=\rho \pi_{t}^{B}-\frac{\theta^{B}}{1+\rho}\left(\frac{2 \gamma+2 \phi+\phi \gamma+2 \phi^{2}-\gamma \alpha}{\gamma} p_{t}+\frac{\gamma^{2}-2 \gamma+2 \gamma \phi-2 \phi}{\gamma} c_{C, t}-(1+\phi) a_{t}\right) .
\end{aligned}
$$


Proposition 6. For $\gamma=1$, the 2 New Keynesian Phillips Curves of our model are given by

$$
\begin{aligned}
& \dot{\pi}_{t}^{A}=\rho \pi_{t}^{A}-\frac{\theta^{A}}{1+\rho}\left(c_{C, t}+\kappa_{p} p_{t}-(1+\phi) a_{t}\right) \\
& \dot{\pi}_{t}^{B}=\rho \pi_{t}^{B}-\frac{\theta^{B}}{1+\rho}\left(\left(\kappa_{p}+2(1-\alpha)\right) p_{t}-c_{C, t}-(1+\phi) a_{t}\right),
\end{aligned}
$$

where $\kappa_{k}=3 \phi+2 \phi^{2}+\alpha$.

These Phillips curves highlight both the earnings and expenditure channels of the model.

Finally, to derive the dynamic (IS) equation, note that

$$
\begin{aligned}
& P_{C, t}=\left(P_{t}^{A}\right)^{1-\alpha^{C}}\left(P_{t}^{B}\right)^{\alpha^{C}} \\
& p_{C, t}=\left(1-\alpha^{C}\right) p_{t}^{A}+\alpha^{C} p_{t}^{B},
\end{aligned}
$$

Hence,

$$
\pi_{C, t}=\dot{p}_{C, t}=(1-\alpha) \pi_{t}^{A}+\alpha \pi_{t}^{B}
$$

Proposition 7. For $\gamma=1$, the dynamic IS equation of our model is given by

$$
\dot{c}_{C, t}=i_{t}-(1-\alpha) \pi_{t}^{A}-\alpha \pi_{t}^{B} .
$$

